\title{
Genetic and molecular characterization of multicomponent resistance of Pseudomonas against allicin
}

Jan Borlinghaus ${ }^{1} \mathbb{D}$, Anthony Bolger ${ }^{2}$, Christina Schier ${ }^{1}$, Alexander Vogel², Björn Usadelº, Martin CH Gruhlke, Alan J Slusarenko ${ }^{1}$ (1)

The common foodstuff garlic produces the potent antibiotic defense substance allicin after tissue damage. Allicin is a redox toxin that oxidizes glutathione and cellular proteins and makes garlic a highly hostile environment for non-adapted microbes. Genomic clones from a highly allicin-resistant Pseudomonas fluorescens (PfAR-1), which was isolated from garlic, conferred allicin resistance to Pseudomonas syringae and even to Escherichia coli. Resistance-conferring genes had redox-related functions and were on core fragments from three similar genomic islands identified by sequencing and in silico analysis. Transposon mutagenesis and overexpression analyses revealed the contribution of individual candidate genes to allicin resistance. Taken together, our data define a multicomponent resistance mechanism against allicin in PfAR-1, achieved through horizontal gene transfer.

DOI 10.26508/Isa.202000670 | Received 7 February 2020 | Revised 14 March 2020 | Accepted 16 March 2020 | Published online 31 March 2020

\section{Introduction}

Plants produce a vast array of secondary metabolites, many of which are involved in defense against microbes, resulting in a dynamic coevolutionary arms race in the interaction between plants and their associated microorganisms (Burdon \& Thrall, 2009). Plants provide habitats for commensal and pathogenic organisms and generally it is assumed that microorganisms found in association with a given plant host are adapted to that ecological niche as part of the microbiota. Adaptation is the process that tailors organisms to a particular environment and enhances their evolutionary fitness, and the organosulfur compounds produced by garlic (Allium sativum L.) provide an important example of this scenario. The potent antibacterial activity of garlic is mainly due to diallylthiosulfinate (allicin) (Cavallito \& Bailey, 1944; Cavallito et al, 1944). Allicin, which is responsible for the typical odor of freshly crushed garlic, is formed by the action of alliin lyase (E.C.4.4.1.4) on alliin (S-allyl-L-cysteine sulfoxide) when the enzyme and substrate mix after damage to garlic tissues. The reaction proceeds rapidly, and alliin conversion to allicin is $97 \%$ complete after $30 \mathrm{~s}$ at $23^{\circ} \mathrm{C}$ (Lawson \& Hughes, 1992). Alliin lyase is one of the most prevalent soluble proteins found in garlic bulbs and leaves, and a single clove of $\sim 10 \mathrm{~g}$ fresh weight can liberate up to $5 \mathrm{mg}$ of allicin (Lawson et al, 1991a; Block, 2010), revealing a major investment of plant resources into this defense system (Van Damme et al, 1992; Smeets et al, 1997; Borlinghaus et al, 2014).

Allicin has multiple sites of action and is a concentration-dependent biocide, active against bacteria, fungi, oomycetes, and mammalian cells (Borlinghaus et al, 2014). Allicin is an electrophile that oxidizes thiols, or more precisely the thiolate ion, in a modified thiol-disulfide exchange reaction, producing S-allylmercapto disulfides (Miron et al, 2000; Müller et al, 2016). Cellular targets include accessible cysteines in proteins, and the cellular redox buffer glutathione (GSH). In this way, allicin can inhibit essential enzymes (Wills, 1956) and shift the cell redox balance (Gruhlke et al, 2010), causing oxidative stress. Indeed, at sublethal doses, allicin was shown to activate the Yap1 transcription factor that coordinates the protective oxidative stress response in yeast (Gruhlke et al, 2017). There are indications that the allicin target and cellular redox buffer glutathione (GSH) plays a central role in enabling cells to resist the effects of allicin (Gruhlke et al, 2010, 2017; Leontiev et al, 2018). Allicin reversibly Sthioallylates a range of proteins in bacteria and human cells which can lead to loss of function of essential enzymes (Müller et al, 2016; Chi et al, 2019; Gruhlke et al, 2019; Loi et al, 2019; Wüllner et al, 2019).

Sensitivity to allicin varies between different bacteria, but the basis for this is unknown (Reiter et al, 2017). We isolated a highly allicinresistant Pseudomonas fluorescens, PfAR-1, from a clove of garlic. How resistance against allicin might be conditioned in PfAR-1 and how it arose are intriguing questions. One possibility for the acquisition of multicomponent resistance is horizontal gene transfer (HGT), that is, the sharing of genetic material between organisms that are not in a parent-offspring relationship. Large, chromosomally integrated regions obtained by HGT are referred to as genomic islands (GIs), and these are known to expand the ecological niches of their host bacteria for complex and competitive environments (Soucy et al, 2015). Gls generally show a different average GC content and codon usage to the rest of the ${ }^{1}$ Department of Plant Physiology, Rheinisch-Westfälische Technische Hochschule Aachen (RWTH Aachen University), Aachen, Germany ${ }^{2}$ Department of Botany,
Rheinisch-Westfälische Technische Hochschule Aachen (RWTH Aachen University), Aachen, Germany

Correspondence: jan.borlinghaus@rwth-aaachen.de; alan.slusarenko@bio3.rwth-aachen.de 
genome. HGT is a widely recognized mechanism for adaptation in bacteria, and microbial antibiotic resistance and pathogenicity traits are often associated with HGT (MacLean \& San Millan, 2019).

In the study reported here, we isolated a highly allicin-resistant bacterium from its ecological niche on garlic, an environment hostile to non-adapted microorganisms, and we used a shotgun genomic cloning strategy to functionally identify genes conferring allicin resistance. The annotated functions of resistance-conferring genes throw light on the complex molecular mechanisms of resistance of PfAR-1 to allicin, a redox toxin which has multiple effects within cells. This functional approach was complemented by whole-genome sequencing which revealed unique genomic features in comparison with other Pseudomonads. Both approaches independently identified the same sets of genes, validating the strategy. The multiple copies of the genes conferring allicin resistance, gained by horizontal transfer and duplication events, emphasize the evolutionary investment associated with allicin resistance in PfAR-1 that presumably enables it to exploit garlic as an environmental niche.

\section{Results}

\section{An allicin-resistant $P$. fluorescens from garlic}

We reasoned that if allicin-resistant bacteria were to be found in nature, it would likely be in association with garlic cloves. Therefore, the degree of allicin resistance of bacteria isolated from garlic bulbs was tested in a Petri plate agar diffusion test with bacteria-seeded agar. An isolate that was able to grow right up to the allicin solution was detected. In comparison, allicin-sensitive Escherichia coli DH5a and Pseudomonas syringae pv. phaseolicola Ps4612 showed large inhibition zones (Fig 1A). The allicin-resistant isolate was identified by Sanger sequencing of the ribosomal internal transcribed spacer as $P$. fluorescens and was named PfAR-1 (P. fluorescens Allicin Resistant-1).

PfAR-1 genomic clones were shotgun electroporated into cells of highly allicin-sensitive Ps4612. In all, $1.92 \times 10^{8}$ clones were screened, giving $\sim 33 \times$ library coverage. Resistant recipients were selected on allicin-containing medium, and eight resistant transformants were confirmed in streak tests (Fig 1B). Restriction analysis revealed that the resistance-conferring PfAR-1 clones were all $\sim 10 \mathrm{~kb}$ in size.

In both E. coli and PS1448A, it was found that PfAR-1 clones conferred resistance to allicin but not to the other oxidants tested (Fig 1C). The degree of allicin resistance conferred by genomic clones 1 and 5 was similar, but clone 8 was less effective than the other clones (Fig 1C). The different oxidizing agents tested cause different stresses in cells. Thus, allicin S-thioallylates -SH groups, which is a reversible thiol modification similar to glutathiolation (Gruhlke et al, 2019). Whereas $\mathrm{H}_{2} \mathrm{O}_{2}$ is a reactive oxygen species that reacts poorly with - $\mathrm{SH}$ groups and is largely removed from cells by peroxiredoxins (Winterbourn \& Hampton, 2008; Poole, 2015), CHPO causes lipid peroxidation (Halliwell \& Gutteridge, 2015), and N-ethylmaleimide (NEM), although oxidizing -SH groups, does so irreversibly. The results show that the clones do not confer resistance to oxidative stress in general, but rather to the type of oxidative stress caused by allicin in particular.

\section{In silico analysis of the PfAR-1 genome}

The PfAR-1 genome was sequenced using a combined Illumina and Pacific Biosciences data set and assembled into a single chromosome, as described in the Materials and Methods section. The genome size was determined to comprise 6,251,798 bp and had an overall GC content of $59.7 \%$. A total of 5,406 putative protein-coding sequences, in addition to 73 tRNAs and 6 rRNA clusters, were detected. With an average nucleotide identity (ANI) of $85.94 \%$ (determined with OrthoANI software, [Lee et al, 2016]), the closest relative to PfAR-1 in the databases was $P$. fluorescens reference strain Pf0-1, supporting the prior internal transcribed spacer-based identification.

Sanger sequencing of the clone ends was used to identify the origin of the clones within the sequenced PfAR-1 genome. This revealed that clones 1 and 8 had unique origins, whereas clones 2-7 were identical. Thus, three relatively compact allicin resistanceconferring genomic regions had been identified. Genes carried on the clones had preponderantly redox-related functions (Fig 2A and B and Table 1), which fits with allicin's redox toxin mode of action. The overall arrangement of the genes was highly conserved among the clones. Clones 1-7 contained two sets of genes, both of which were conserved in the direction of transcription: osmC, sdr, tetR, $d s b A$, and trx; and ahpD, oye, 4-ot, RefF, and kefC, respectively (Fig 2C). Clone 8, which conferred slightly less allicin resistance than the other clones (Fig 1C), lacked $a h p D$ and oye genes. The kefF and kefC genes are part of a glutathione-regulated $\mathrm{K}^{+}$efflux $/ \mathrm{H}^{+}$influx system and are classified as transporters, although they too are regulated by cellular glutathione and, thus, are redox-dependent.

$P$. fluorescens Pf0-1 is PfAR-1's closest sequenced relative. Nonetheless, dot matrix alignment of the PfO- 1 and PfAR-1 genomes revealed substantial differences. The PfAR-1 chromosome had a central inverted region with respect to $P f 0-1$, and three large GIS with lower GC content ( $<55 \%$ ), which were absent in Pf0-1 (Fig $3 \mathrm{~A}$ and B). The combination of low GC content and absence from the genome of a near-relative suggests that these regions might have arisen by HGT. Further analysis revealed that each of the three GIS (GI1, GI2, and GI3) contained a highly similar region, which we labeled repeat RE1, RE2, and RE3, respectively. The genes within these repeat regions had many annotations in common and a syntenic organization (Table S1), suggesting a shared origin.

It is unusual for multiple copies of genes to be maintained in bacteria without a clear selective advantage because of the genomic instability that arises through homologous recombination leading to genome rearrangements and loss of essential interim sequences (Rocha, 2003). Intriguingly, the allicin resistance-conferring clones found in the functional analysis originated within these three repeat regions (Fig 3B-E), suggesting that the selective advantage may be, in fact, the increased allicin resistance. Possible origins for the putative HGT regions into the PfAR-1 genome were investigated more closely.

Genes on RE1 and RE2 appeared more closely related to each other than to those on RE3 from both a gene commonality (Jaccard similarity of $90 \%$ for RE1 versus RE2, compared with $54.2 \%$ for RE1 versus RE3, and $50 \%$ for RE2 versus RE3) and amino acid-similarity perspective ( $97.5 \%, 87.1 \%$, and $87.2 \%$, respectively). This suggested that RE1 and RE2 originated from a more recent sequence duplication and that RE3 resulted from an earlier duplication event from the common ancestor of RE1 and RE2. To determine the distribution of similar REs within the Pseudomonas genus, we arranged these sequences to form a bait set, and compared this against all 3,347 available Pseudomonas genomes. Similar regions to the bait were detected in eight of the complete genomes, of which six were from plant-pathogenic or plant-associated 


\section{A}
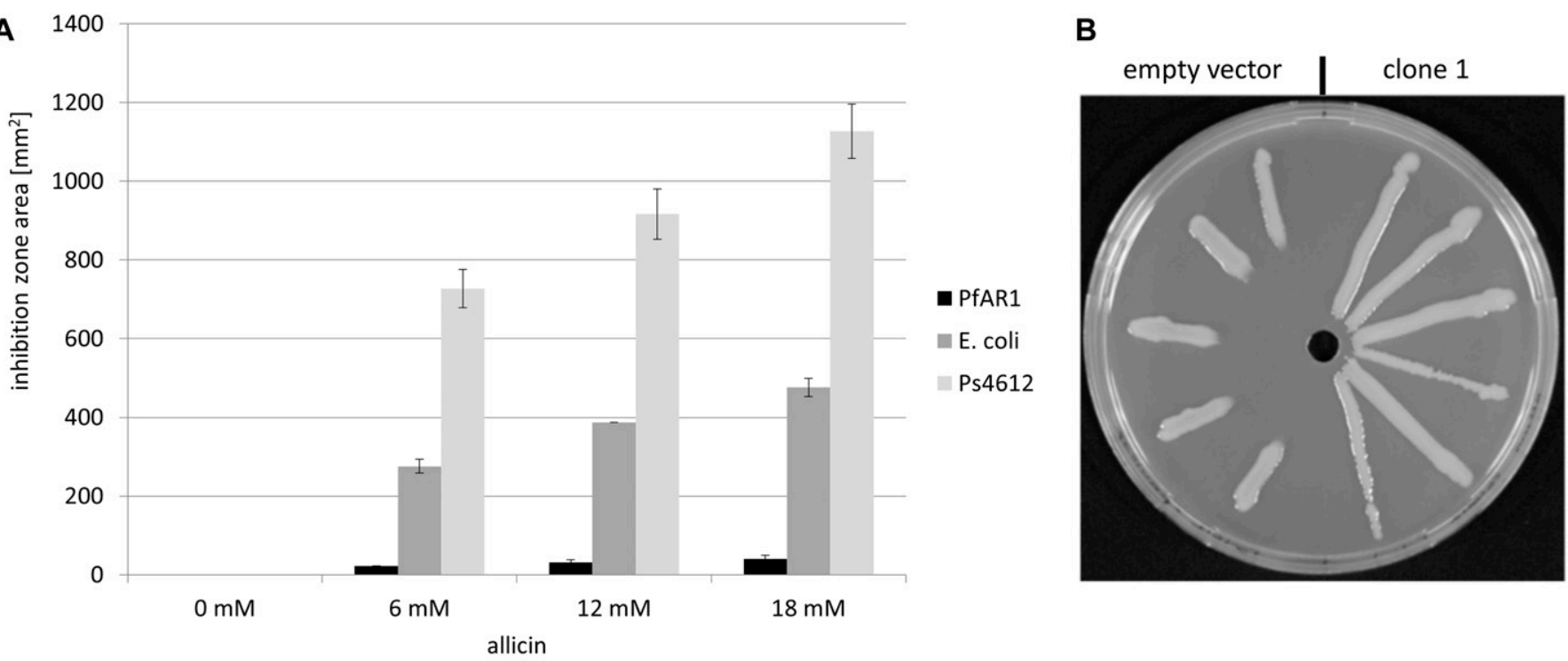

C

Allicin

$\mathrm{H}_{2} \mathrm{O}_{2}$ : Hydrogen peroxide

NEM: N-ethyl maleimide

CHPO: Cumene hydroperoxide<smiles>C=CCSS(=O)CC=C</smiles><smiles>OO</smiles><smiles>CCN1C(=O)C=CC1=O</smiles><smiles>CC(C)(O)c1ccccc1</smiles>

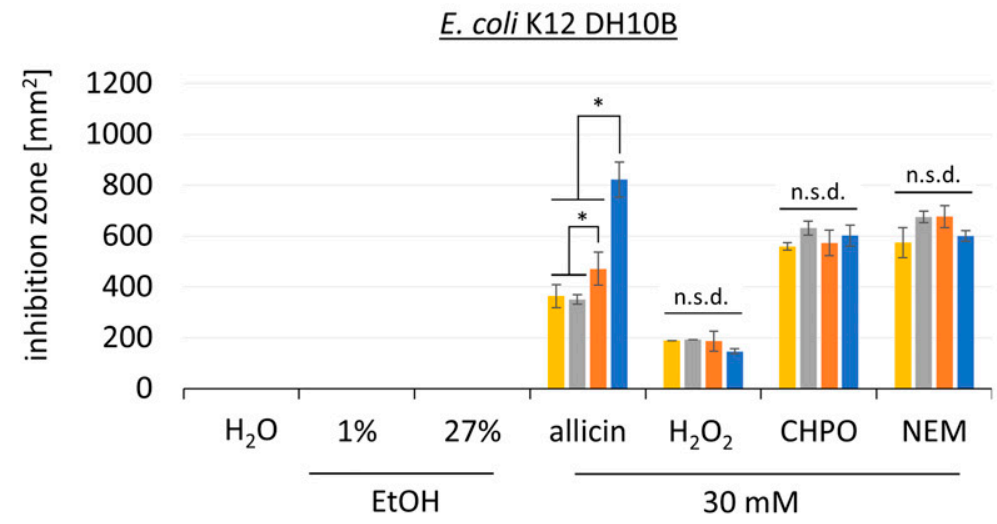

... + PfAR-1 gDNA clone 1

... + PfAR-1 gDNA clone 8

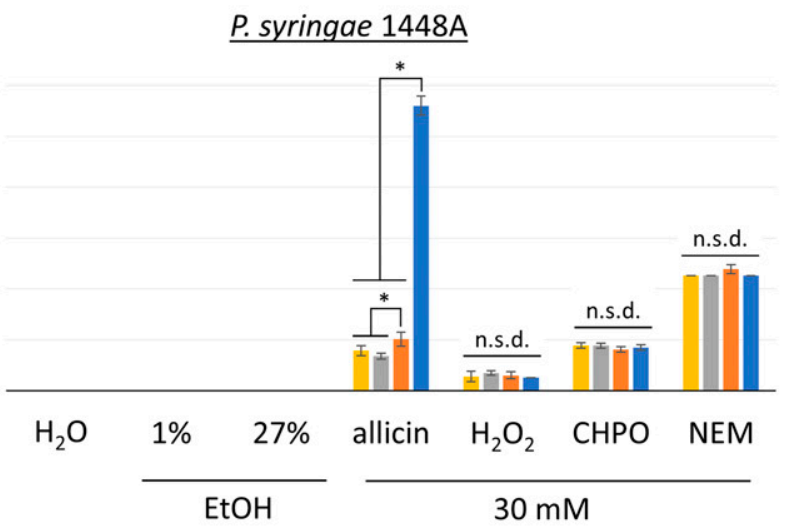

... + PfAR-1 gDNA clone 5

... + empty vector (pRU1097)

Figure 1. PfAR-1 is highly allicin-resistant and discrete genomic clones conferred allicin resistance.

(A) Comparison of the sensitivity of PfAR-1, E. coli DH5 $\alpha$, and P. syringae Ps 4612 to allicin. The area of the inhibition zones in an agar diffusion test is shown for $40 \mu \mathrm{L}$ of 0-18 mM allicin applied centrally to a well in the seeded agar medium. $n=3$ technical replicates. (B) Allicin resistance was conferred by genomic clones from PfAR-1 electroporated into Ps4612. On the left half of the Petri plate, Ps4612 cells contain empty vector and on the right half Ps4612 cells were transformed with vector containing genomic clone 1. The central wells contained $30 \mu \mathrm{l}$ of $32 \mathrm{mM}$ allicin solution. (C) $40 \mu \mathrm{l}$ of $30 \mathrm{mM}$ allicin, $\mathrm{H}_{2} \mathrm{O}_{2}, \mathrm{~N}$-ethylmaleimide (NEM), or cumene hydroperoxide (CHPO) were applied to wells cut in agar with a surface lawn of dispersed bacteria. Ethanol was used as a solvent for NEM and $\mathrm{CHPO}$ and $1 \%$ and $27 \%$ ethanol, respectively, were included as controls. Areas of the inhibition zones are shown for the recipients containing genomic clones $1,5,8$, or the empty vector $(n=3$ or more technical replicates, * $P<0.05$, Holm-Sidak method for all pairwise comparison). n.s.d., no significant difference. Each experiment was performed twice. Error bars indicate standard deviation.

pseudomonads. Matching regions were also found in 56 of the draft genomes, eight of which showed two copies of the region. One of the draft genomes had the matching region split across two contigs, although this was presumably due to incomplete assembly, rather than representing a biological signal. These similar regions ranged from effectively complete, with hits from all 26 bait groups, to 
A

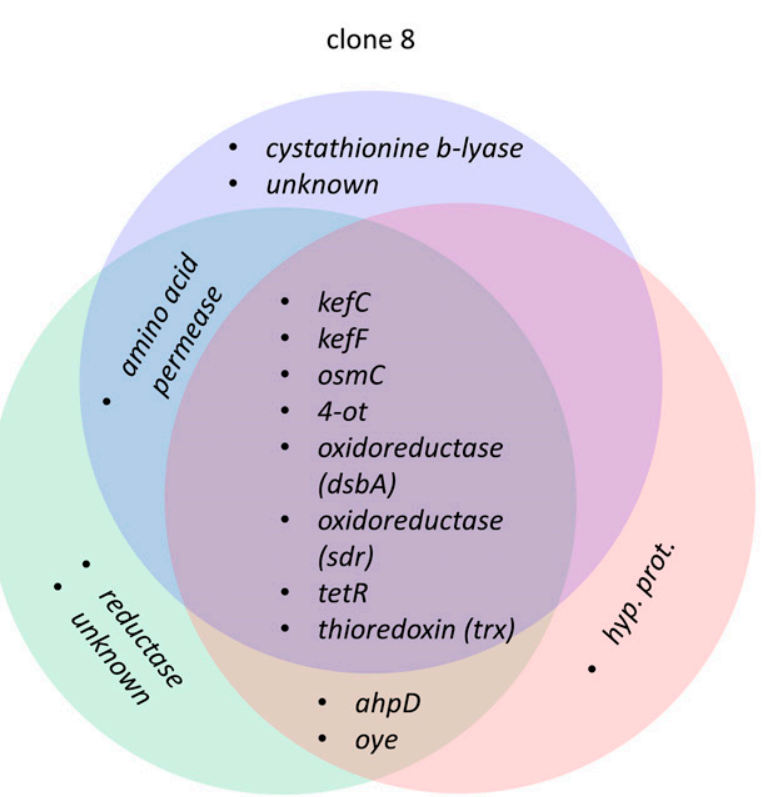

clones $2,3,4,5,6,7$

clone 1

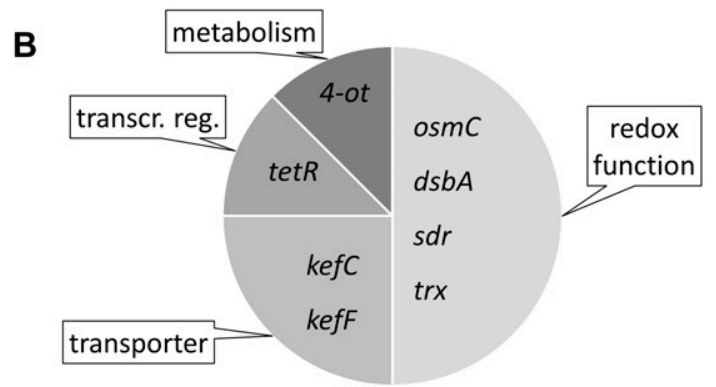

functions of the 8 congruent genes in all clones

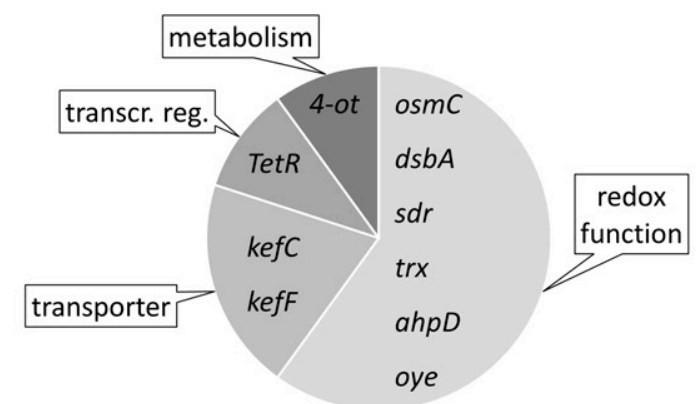

functions of the 10 congruent genes in clones 1-7

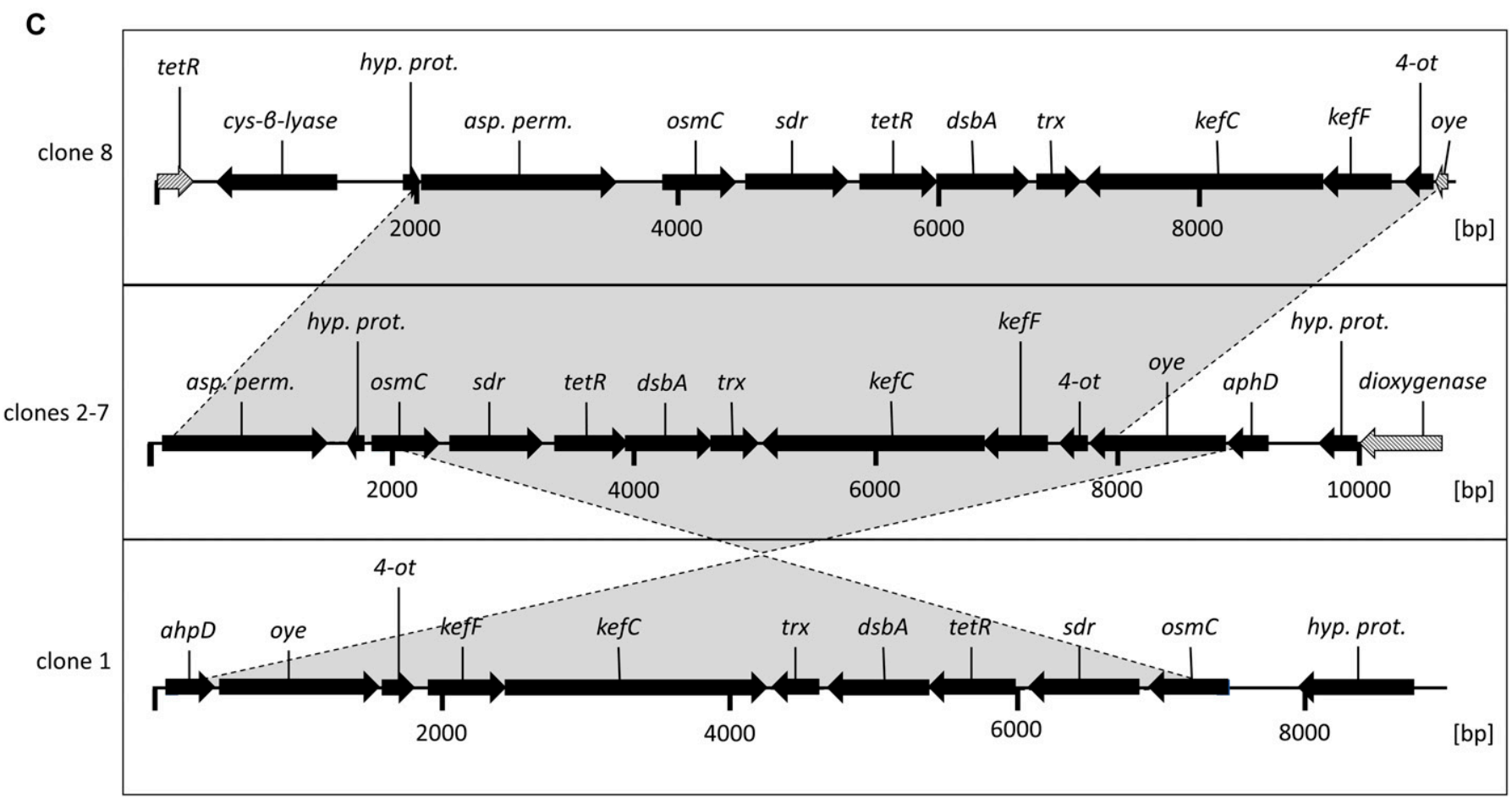

Figure 2. Characteristics of the allicin resistance-conferring PfAR-1 genomic clones.

(A) Venn diagram showing congruent genes. Annotation is based on protein domains and corresponding families, proteins with no similarities are labelled unknown. (B) Congruent genes grouped by function. (C) Arrows show the direction of transcription. Grey-shaded arrows in clones 8 and 2-7 represent truncated genes (the genes are annotated fully in Table 1).

highly divergent with only five of the bait groups found. Of the 56 partial genome sequences, 37 were from plant-pathogenic or plantassociated bacteria (Table S2).

Expecting the codon usage of a horizontally transferred gene region to resemble the donor species rather than the current host, we performed a codon usage analysis to complement the bait sequence analysis described above. For this, we compared the full PfAR-1 genome, the three RE regions, the 3,347 other available Pseudomonas genomes, and eight representative non-Pseudomonas Gammaproteobacteria. The results were 
Table 1. Congruent set of genes identified in the genomic clones 1-7 that conferred allicin resistance to E. coli K12 DH10B and P. syringae pv. phaseolicola 4612.

\begin{tabular}{|c|c|c|}
\hline PfAR-1 genes ${ }^{\mathrm{a}}$ & Reported function in other bacteria & References \\
\hline Alkylhydroperoxidase (ahpD) & $\begin{array}{l}\text { Part of the carboxymuconolate decarboxylase } \\
\text { family. NADH-dependent AhpD/AhpC system } \\
\text { confers oxidative stress resistance in } \\
\text { Mycobacterium tuberculosis. }\end{array}$ & Bryk et al (2002) and Koshkin et al (2003) \\
\hline Old yellow enzyme (oye) & $\begin{array}{l}\text { OYE protein family contains a diverse set of } \\
\mathrm{NADPH} \text {-dependent dehydrogenases that reduce } \\
\alpha, \beta \text { unsaturated aldehydes and ketones. OYE was } \\
\text { reported to be part of the oxidative stress } \\
\text { response in yeast and in Bacillus. }\end{array}$ & $\begin{array}{l}\text { Stott et al (1993), Vaz et al (1995), Fitzpatrick et al } \\
\text { (2003), and Trotter et al (2006) }\end{array}$ \\
\hline 4-oxalocrotonate tautomerase (4-ot) & $\begin{array}{l}\text { 4-OT converts 2-hydroxymuconate to the } \\
\alpha, \beta \text {-unsaturated ketone 2-oxo-3-hexendioate. }\end{array}$ & Whitman et al (1991) and Whitman (2002) \\
\hline $\begin{array}{l}\text { Glutathione-regulated potassium-efflux system } \\
\text { protein F (kefF) }\end{array}$ & $\begin{array}{l}\text { KefF is a cytoplasmic regulator of KefC. KefF is } \\
\text { activated by glutathione-adducts and } \\
\text { subsequently activates KefC. }\end{array}$ & \multirow{2}{*}{$\begin{array}{l}\text { Meury and Kepes (1982), Elmore et al (1990), } \\
\text { Douglas et al (1991), Munro et al (1991), Ferguson e } \\
\text { al (1997), Miller et al (2000), and Lyngberg et al } \\
\text { (2011) }\end{array}$} \\
\hline $\begin{array}{l}\text { Glutathione-regulated potassium-efflux system } \\
\text { protein C (kefC) }\end{array}$ & $\begin{array}{l}\text { KefC is a proton import/potassium export } \\
\text { antiporter. KefC activity is tightly regulated by } \\
\text { glutathione and KefF. Active KefC confers } \\
\text { resistance against electrophiles such as N- } \\
\text { ethylmaleimide in E. coli. }\end{array}$ & \\
\hline Thioredoxin (trx) & $\begin{array}{l}\text { Trx are dithiol-disulfide oxidoreductases that } \\
\text { help to maintain the thiol groups of proteins in a } \\
\text { reduced state }\end{array}$ & Holmgren (2000) \\
\hline Disulfide bond protein A (dsbA)/frnE-like & $\begin{array}{l}\text { DsbA in E. coli is responsible for introduction of } \\
\text { disulfide bonds in nascent polypeptide chains in } \\
\text { the periplasmic space. Other Dsb members show } \\
\text { chaperone-like functions. FrnE is a member of the } \\
\text { DsbA family and was reported to confer oxidative } \\
\text { stress resistance in Deionococcus radiodurans. }\end{array}$ & $\begin{array}{l}\text { Bardwell et al (1991), Kamitani et al (1992), and } \\
\text { Khairnar et al (2013) }\end{array}$ \\
\hline Transcriptional regulator (tetR) & $\begin{array}{l}\text { Transcriptional repressors widely distributed } \\
\text { among different bacteria. }\end{array}$ & Ramos et al (2005) \\
\hline Short chain dehydrogenase (sdr) & $\begin{array}{l}\text { The family contains dehydratases, } \\
\text { decarboxylases or simple oxidoreductases. }\end{array}$ & Kavanagh et al (2008) \\
\hline Osmotically inducible protein C (osmC) & $\begin{array}{l}\text { The family contains peroxiredoxins which play a } \\
\text { role in oxidative stress defense. OsmC confers } \\
\text { resistance to organic hydroperoxides such as } \\
\text { cumene hydroperoxide in E. coli. }\end{array}$ & Lesniak et al (2003) \\
\hline
\end{tabular}

${ }^{a}$ Annotation is based on protein domains and corresponding protein families.

plotted using principal component analysis and are shown in Fig S1.

The first principal component, which accounts for almost $78 \%$ of the variation, seems to reflect the GC content, ranging from Acinetobacter baumannii with a GC content of $38.9 \%$ on one extreme to Rugamonas rubra with $67 \%$ GC content on the other, and unsurprisingly, given their usually low GC content, separates the putative HGT regions from not only the PfAR-1 whole genome but also from the vast majority of other Pseudomonas genomes. The second principal component also separates the putative HGT regions from the other genomes, although this component should not be overinterpreted because it accounts for only $6.5 \%$ of variation. The resulting plot loosely clusters the three Gl regions with four sequenced Pseudomonas species, namely, Pseudomonas luteola, Pinguicula lutea, Pseudomonas zeshuii and Pseudomonas sp. HPB0071. Unfortunately, none of these four species were found to contain matches for the bait sequences in the cross-species comparison above, and thus, they are unlikely to be the origin of the putative HGT regions.

Regions which have been horizontally transferred have, by definition, an evolutionary history distinct from their host genomes. We, therefore, created a phylogenetic tree for the RE-like regions across the Pseudomonas clade, comprising the three RE regions from PfAR1 , plus 72 RE-like regions from other species. This was then compared with a whole-genome phylogenetic tree of 280 Pseudomonas spp. supplemented by four more distant genomes, namely, Azotobacter vinelandii DJ, A. baumannii AC29, E. coli K12 MG1655, and Burkholderia cenocepacia J2315, which served as an outgroup. The 280 Pseudomonas genome subsets consisted of a) all 215 complete genomes, b) the 56 draft genomes showing a substantial hit against the Repeat Region bait set, as described above, and c) nine Pseudomonas genomes with unusual codon usage ( $P$. lutea, P. luteola, Pseudomonas sp HPB0071, Pseudomonas sp FeS53a, P. zeshuii, Pseudomonas hussainii JCM, P. hussainii MB3, Pedobacter Caeni, and Prauserella 
A
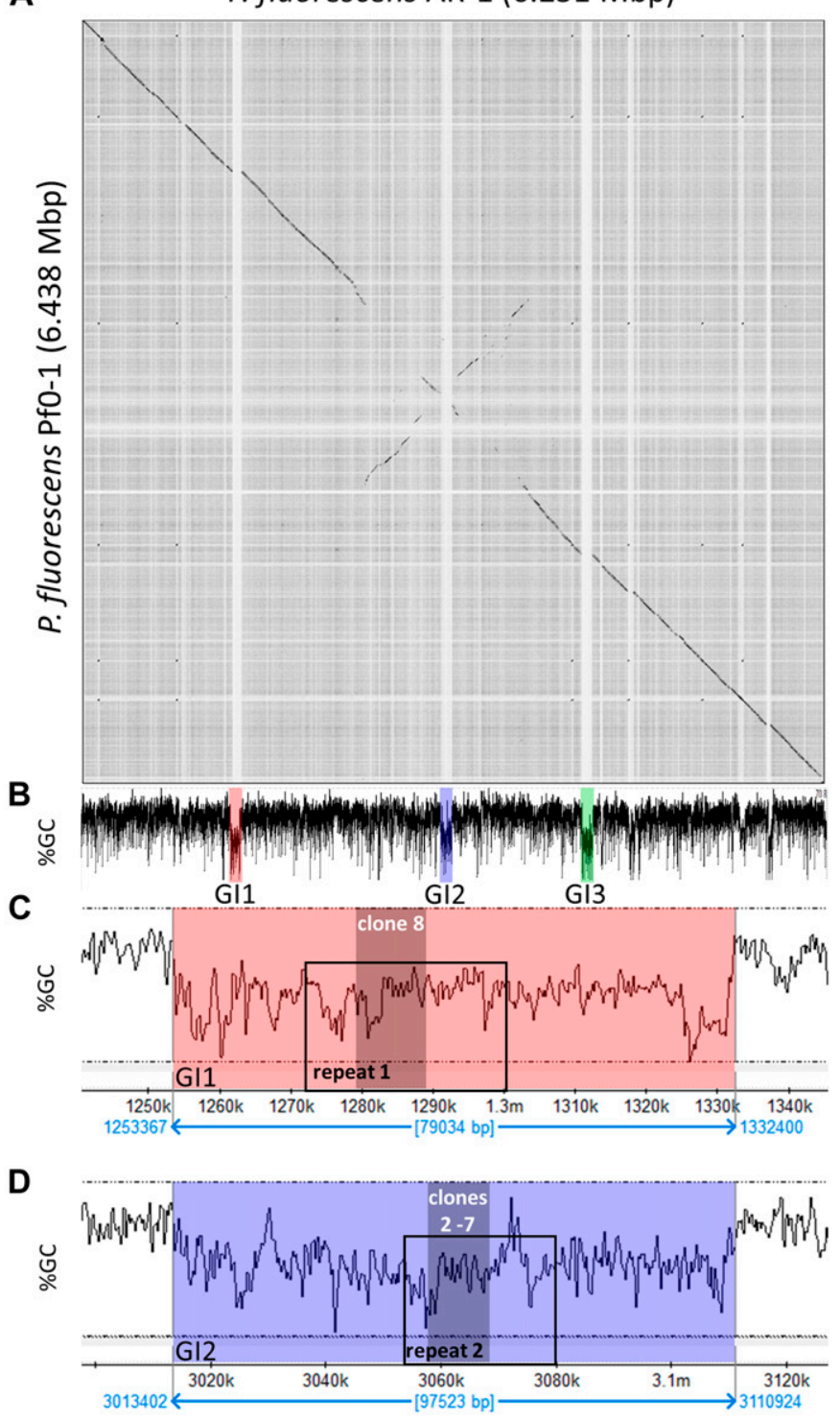

E

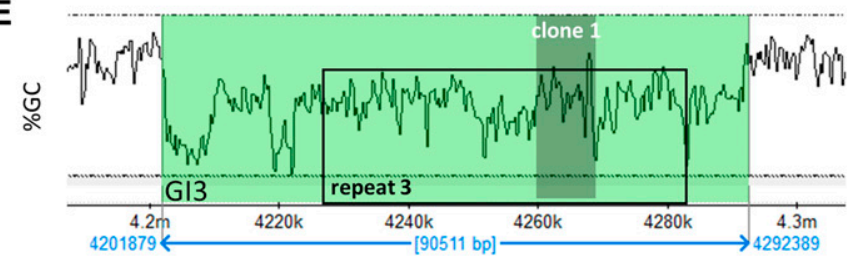

Figure 3. Genomic characteristics of PfAR-1.

(A) Dot plot alignment of the PfAR-1 and PfO-1 genomes. Numbering is from the putative origin of replication (oriC) loci. The disjunctions arising because of inserts in PfAR-1 not present in PfO-1 are clearly visible. (B) The GC content of the PfAR-1 chromosome with GI1, GI2, and GI3 marked in red, blue, and green, respectively. (C) The low GC content region GI1 enlarged to show the position of repeat 1 (RE1) and the location of allicin resistance-conferring genomic clone 8. (D) The low GC content region GI2 enlarged to show the position of RE2 and the location of allicin resistance-conferring genomic clones 2-7. (E) The low GC content region GI3 enlarged to show the position of RE3 and the location of allicin resistance-conferring genomic clone 1. endophytica). It is immediately apparent from comparison of the resulting region and whole-genome trees that the RE-like regions have a distinct evolutionary history (Supplemental Data 1). For independent confirmation of the above analysis, IslandViewer 4 (Bertelli et al, 2017) was used to assess the PfAR-1 genome for HGT events. This analysis also clearly identifies the three putative HGT regions, although additional weaker candidate regions are also indicated (Fig S2).

\section{$a h p D, d s b A$, and gor can individually confer high allicin resistance}

The contribution of individual genes to allicin resistance was investigated by transposon mutagenesis of clone 1 in E. coli and screening Tn mutants for loss of function. In addition, subcloning and overexpression of individual genes in Ps4612 was undertaken to assess for gain of function.

A decrease in allicin resistance compared with non-mutagenized genomic clone 1 was shown by 86 of 132 Tn mutants investigated in a streak assay. Tn mutants were examined by sequencing. No Tn insertions were found in the osmC, sdr, or tetR genes, but for most of the remaining genes, several independent Tn insertion sites were found. Tn mutants in each gene (Fig 4A) were tested for an increased allicin sensitivity phenotype in a drop test (Fig 4B). All Tn mutants grew less well in the absence of allicin stress than did controls (wt clone 1 and empty vector), as evidenced by the lower colony density visible at the $10^{-4}$ and $10^{-5}$ dilutions, respectively. No visible effect at either 150 or $200 \mu \mathrm{M}$ allicin compared with clone 1 was observed for Tn insertions in the vector backbone, or the genes encoding the hypothetical protein or kefF, and the downstream region of 4-ot. In contrast, Tn insertions in either $d s b A$, trx, kefC, oye, or ahpD led to a clear increase in allicin sensitivity at both concentrations. ahpD::Th showed by far the highest sensitivity, and the phenotype resembled that of the empty vector control. ahpD potentially codes for an alkylhydroperoxidase, and the data suggest that this protein plays a major role in being able to confer allicin resistance to PfAR-1. The contributions of the $d s b A$ and trx genes to allicin resistance were more than those of the kefC and oye genes, but all of these Tn mutants showed a clear allicin sensitivity phenotype, especially at $200 \mu \mathrm{M}$ allicin (Fig 4B).

The set of congruent genes on clone 1 were cloned individually in an expression vector to investigate the contribution of each gene to allicin resistance. Ps4612 was used for these experiments because we reasoned that even a small gain in resistance should easily be visible in this highly allicin-sensitive isolate. Only $a h p D$ and $d s b A$ conferred a gain of resistance when overexpressed individually. The resistance conferred by ahpD was almost as high as that conferred by the intact clone 1. Overexpression of dsbA in Ps4612 also caused a clear gain of resistance (Fig 4C).

Interestingly, both GI1 and GI2 have a Gor (glutathione reductase) gene (gor2, gor3) outside of the allicin resistance-conferring clones 2-8 in RE1 and RE2, respectively, and a further gor gene (gor1) is present on the PfAR-1 chromosome. Because allicin oxidizes GSH to $S$-allylmercaptoglutathione, which is reduced by Gor to regenerate GSH (Horn et al, 2018), we investigated the potential contribution of Gor to PfAR-1 allicin-resistance. Because PfAR-1 has three gor genes, the experiments were performed with E. coli, which, like most bacteria, has only a single gor gene. Deleting the gor gene from $E$. coli BW25113 increased its sensitivity to allicin and resistance was 
A
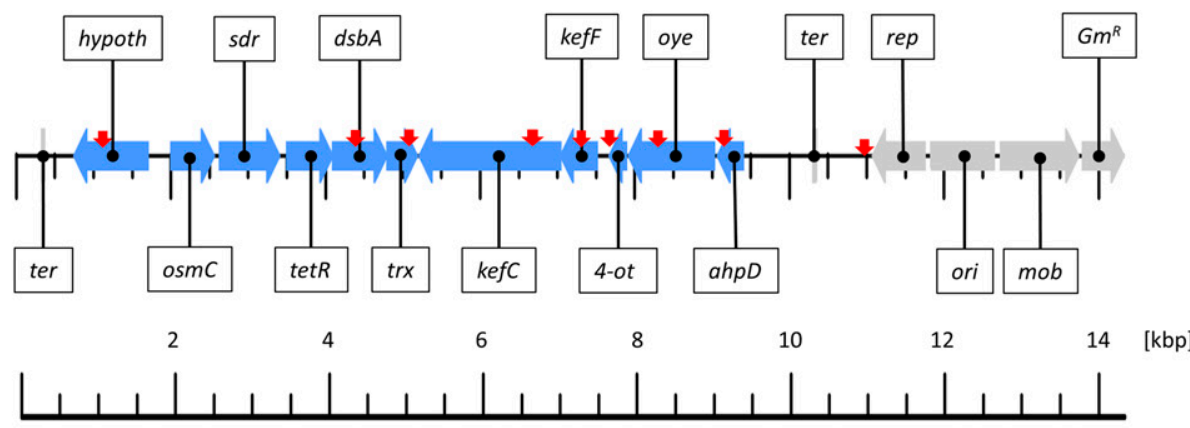

B
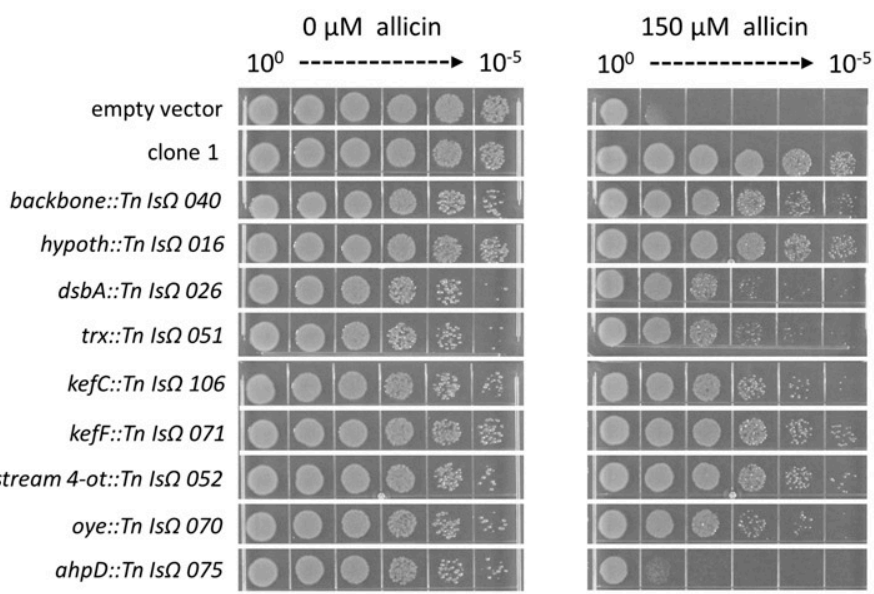

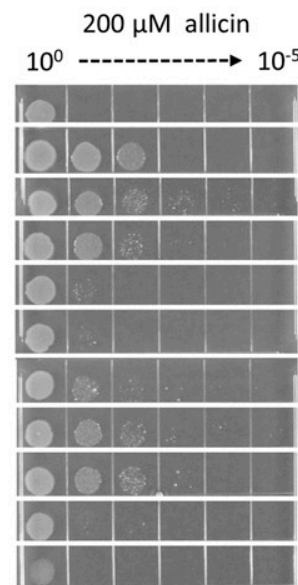

allicin

C

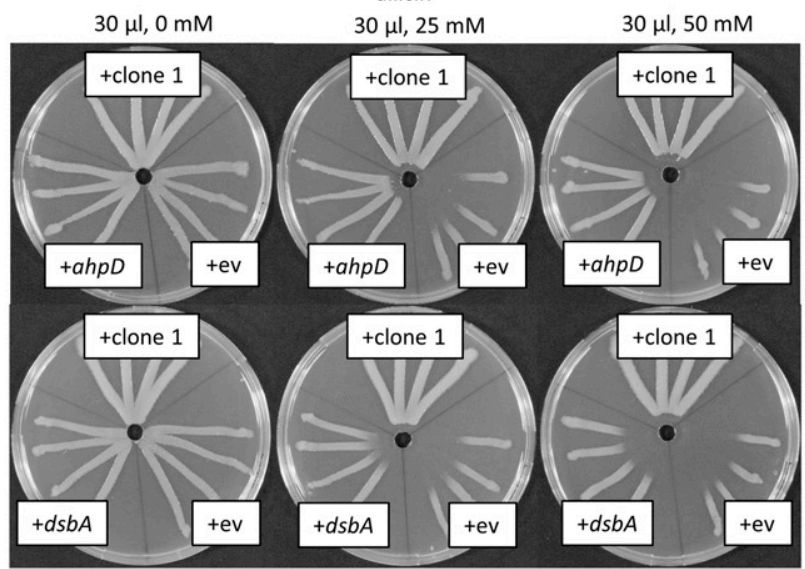

D
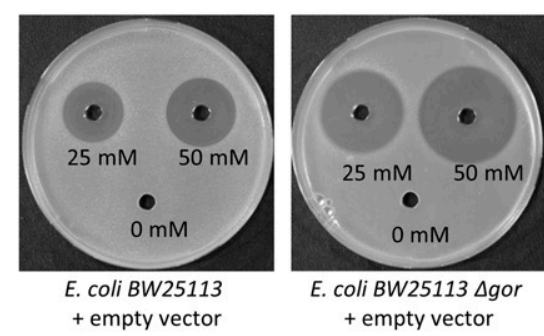

E. coli BW25113 $\Delta$ gor + empty vector

restored by complementing the $\Delta$ gor strain with chromosomal PfAR-1 gor1 (Fig 4D). These results clearly demonstrate the importance of Gor activity for allicin resistance, and in this connection, it is important to note that PfAR-1 not only has three gor genes but also has a twofold higher basal Gor activity than PfO-1 (Fig S3).

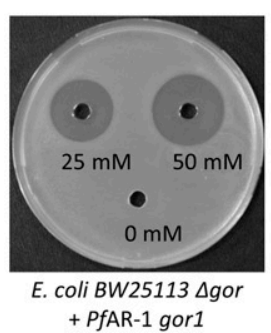

Figure 4. Transposon mutagenesis of genes on clone 1.

(A) Linear genetic map of PfAR-1 genomic clone 1. PfAR-1 genes are shown in blue, whereas genes on the vector backbone are shown in grey. The position of transposon insertions is indicated by red arrows. (B) E. coli MegaX DH10B transformed with clone 1, or empty vector, was compared with transposon insertion mutants in drop tests. All cultures were diluted to $\mathrm{OD}_{600}=1\left(=10^{\circ}\right)$ and $5 \mu \mathrm{l}$ of a $10^{\mathrm{n}}$ dilution series down to $10^{-5}$ was dropped onto LB medium supplemented with different allicin concentrations. The experiment was performed twice. (C) Overexpression of $a h p D$ or $d s b A$ conferred allicin resistance to Ps4612. Test solutions were $30 \mu \mathrm{l}$, water, and 25 or $50 \mathrm{~mm}$ allicin. The experiment was performed twice. (D) PfAR-1 glutathione reductase (gor1) complements E. coli BW25113 glutathione reductase deletion mutant ( $\Delta$ gor). $40 \mu \mathrm{l}$ of allicin solution (or water) were pipetted into wells in E. coli-seeded medium. The experiment was performed twice.

\section{Syntenic regions to PfAR-1 REs in other plant-associated bacteria}

Database searches revealed that some plant-associated bacteria, for example, the garlic pathogen Pseudomonas salomoni ICMP 14252 (Gardan et al, 2002) and a tomato- and Arabidopsis thaliana pathogen 
A
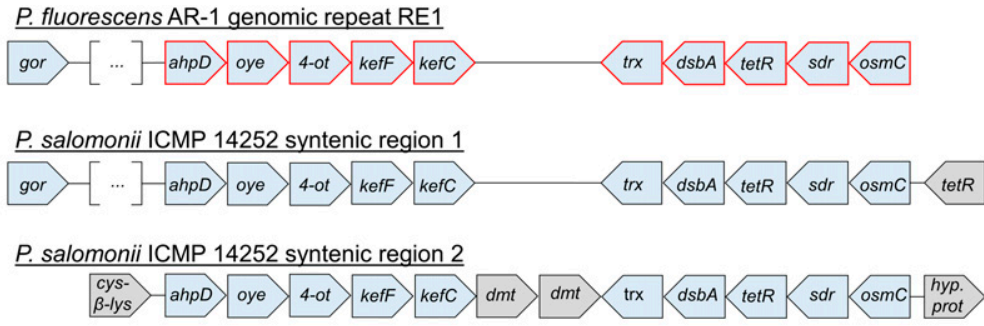

P. syringae pv. tomato $\mathrm{DC} 3000$ syntenic region

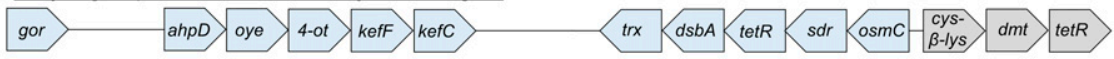

B

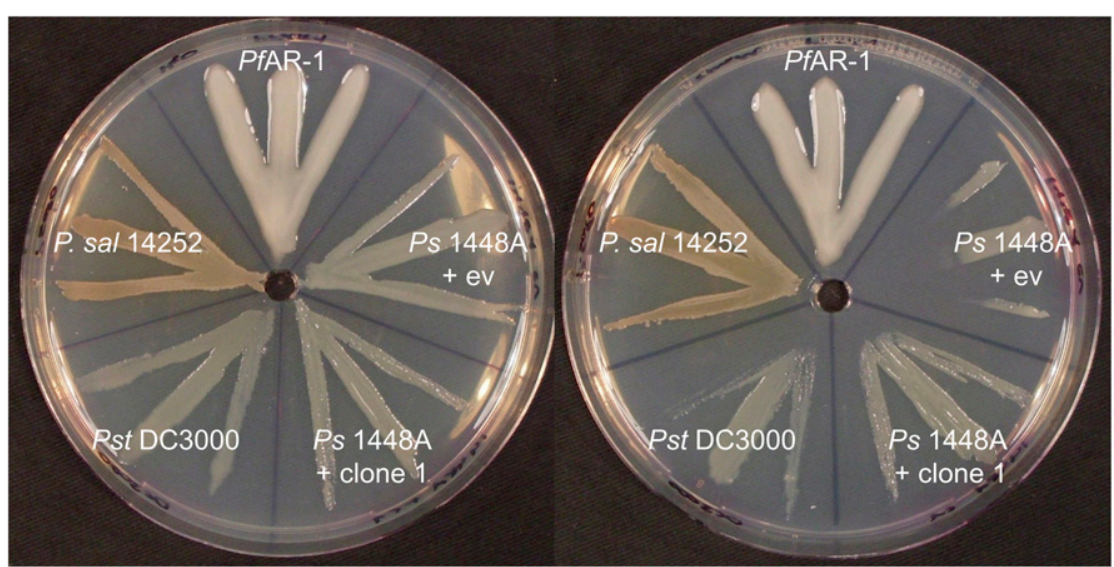

$50 \mu \mathrm{L} \mathrm{H}_{2} \mathrm{O}$
$50 \mu \mathrm{L} 20 \mathrm{mM}$ allicin
Figure 5. The allicin resistance of $P$. salomoni ICMP 14252 , P. syringae $1448 \mathrm{~A}$, and $P$. syringae DC3000 correlates with the number of syntenic regions that contain the core genes for allicin resistance identified in PfAR-1.

(A) A set of 10 genes is conserved in the genomic repeats of PfAR- 1 and in syntenic regions of P. salomoni ICMP 14252 and in P. syringae pv. tomato DC3000. cys- $\beta$-lys, cystathione$\beta$-lyase; $d m t$, permease of the drug/metabolite transporter (dmt) superfamily; the remaining genes are referred to elsewhere in this study. The distance between the different genes does not represent the actual intergenic distances because the gene blocks were graphically aligned to highlight the conservation. In case of gor of PfAR-1 RE1 and $P$. salomoni syntenic region 1 , these genes are further upstream of the highlighted genes with several genes in between (represented by the squared brackets with three dots). Red highlighted genes represent the congruent set of genes also found in the resistance-conferring genomic clones of PfAR-1. Coordinates of syntenic regions are: $P$. salomoni ICMP 14252 (GenBank: FNOX00000000.1) region 1 on contig 102 from position 324,974 to 392,566 , and region 2 on contig 114 from position 73,863 to 86,381 and for P. syringae pv. tomato DC3000 (GenBank: NC_004578.1) from 4,794,584 to 4,807,117. (B) The allicin resistance of different bacteria correlates with the number of gene copies that are syntenic to the core fragment of the genomic clones from PfAR-1. Ps1448A was either transformed with PfAR-1 genomic clone 1 or pRU1097 (empty vector control), whereas the other strains were not genetically modified. PfAR-1 has three copies of a set of 10 genes that were identified on genomic clones (e.g., genomic clone 1) that confer resistance to allicin in P. syringae strain 4612. P. salomoni ICMP 14252 has two copies of this set of genes in its genome, whereas $P$. syringae pv. tomato DC3000 has one and P. syringae 1448A none. The streak test was performed twice.
P. syringae pv. tomato DC3000 (Pst DC3000) (Buell et al, 2003) have regions syntenic with RE1. PfAR-1 RE1 contains a gor gene and two gene groups (from $a h p D$ to kefC and from trx to osmC) that are conserved in RE2 and RE3. These two groups are present in the two syntenic regions in the genome of $P$. salomoni ICMP 14252 and in one syntenic region in Pst DC3000 (Fig 5A). In contrast, the French bean (Phaseolus vulgaris) pathogen Ps1448A has no genes with significant similarity to any of the allicin resistance-conferring congruent gene set from PfAR-1 clones. Ps1448A is fully sequenced (Joardar et al, 2005) and is quite similar at the nucleotide level to Pst DC3000 with an ANI of $86.87 \%$. In comparison, the ANI between PfAR1 and Pf0-1 is $85.94 \%$. A gene window analysis of PfAR-1, Pf0-1, Pst DC3000, and P. salomoni ICMP 14252 suggests that the syntenic regions in DC3000 and ICMP 14252 were gained by HGT (Fig S4).

When PfAR-1 (three copies), P. salomoni ICMP14252 (two copies), Pst DC3000 (one copy), and Ps1448A (no copies) were tested in a simple streak assay, we observed that PfAR-1 and $P$. salomoni are most resistant against allicin, followed by Pst DC3000, then with a much higher sensitivity, by Ps1448A. The transfer of PfAR-1 genomic clone 1 to PS1448A raised its allicin resistance to approximately the same level observed in Pst DC3000 (Fig 5B).

\section{Discussion}

The garlic defense substance allicin is a potent thiol reagent which targets the cellular redox buffer glutathione and accessible -SH groups in proteins (Borlinghaus et al, 2014). Allicin has been shown to S-thioallylate several cysteine-containing proteins in bacteria (Müller et al, 2016; Chi et al, 2019; Loi et al, 2019; Wüllner et al, 2019) and humans (Gruhlke et al, 2019) and has been described as a redox toxin (Gruhlke et al, 2010). S-thioallylation by allicin is reversible and sublethal doses suppress bacterial multiplication for a period of time, the length of which is dose-dependent, before growth resumes (Müller et al, 2016). Because allicin affects such a broad catalogue of cellular proteins, it is not easy for an organism to adapt to it by simple mutation. Thus, adding a lethal dose of allicin to a high-density bacterial culture and plating out for survivors, the routine strategy to isolate antibiotic-resistant mutants, has proven ineffective with allicin. Nevertheless, the sensitivity to allicin varies between different bacterial isolates, but the genetic basis for this variation is unknown. We reasoned that we would most likely find organisms with a high allicin resistance in association with the garlic bulb itself as a niche-habitat. This was indeed the case, and we were able to isolate the highly allicin-tolerant $P$. fluorescens Allicin Resistant-1 (PfAR-1) from garlic. In inhibition zone tests, comparison with E. coli K12 DH5a or P. syringae 4612, PfAR-1 showed an exceptionally high degree of allicin resistance (Fig 1A). To gain an insight into the mechanisms of allicin resistance in PfAR-1, we used parallel approaches of functional testing of random genomic clones and whole-genome sequencing. Interestingly, genomic clones from PfAR-1 were able to confer allicin resistance not only to closely related pseudomonads, but also to distantly related bacteria such as E. coli (Fig 1B and C). 


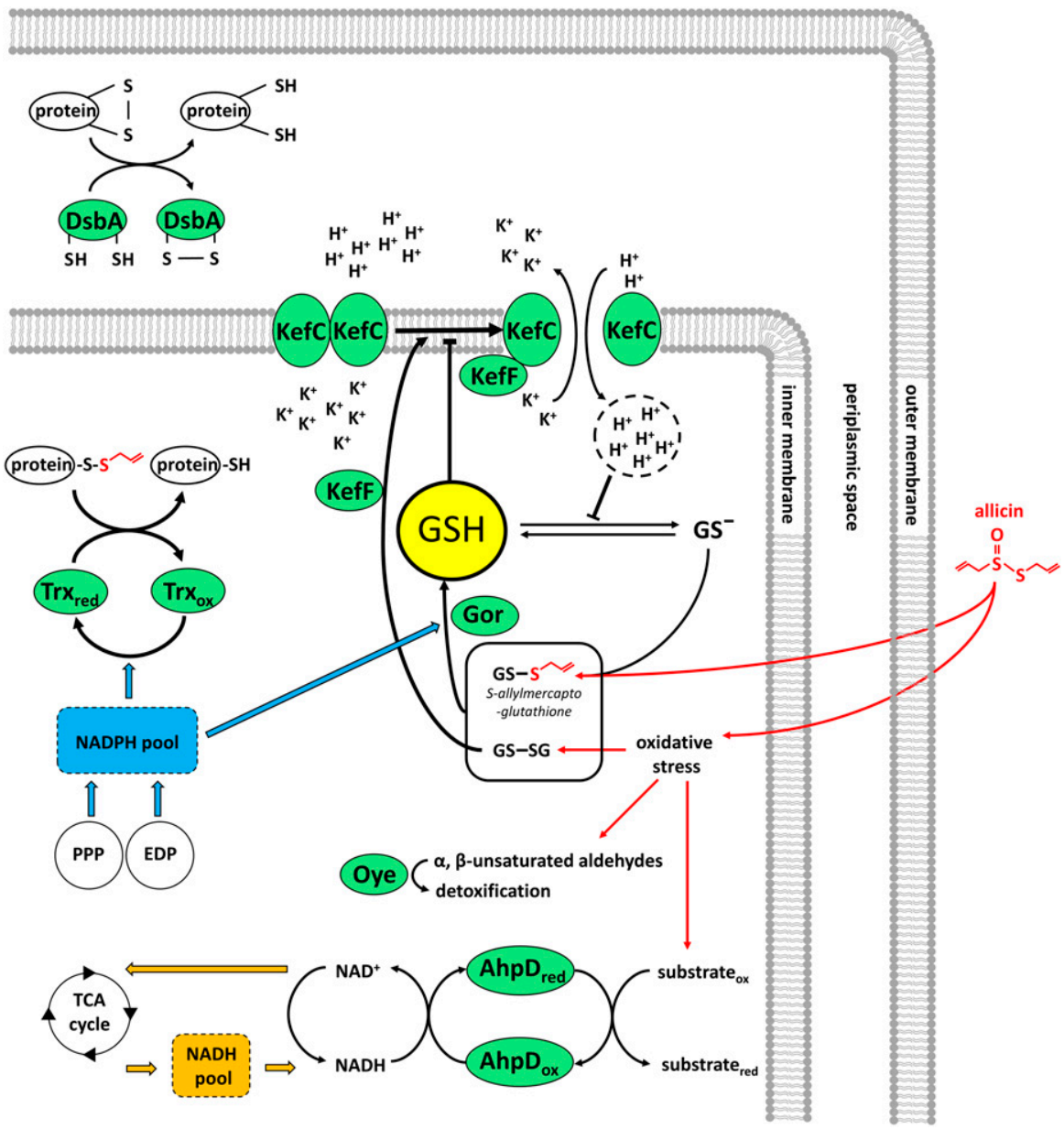

Figure 6. Suggested model for allicin resistance in PfAR-1.

Green ovals show allicin resistance factors identified in PfAR-1. AhpD ${ }_{\text {ox }}, \mathrm{AhpD}_{\text {red, }}$, alkylhydroperoxidase D oxidized or reduced, respectively; DsbA, disulfide bond protein A; EDP, Entner-Doudoroff Pathway; Gor, glutathione reductase; $\mathrm{GS}^{-}$, glutathione as the thiolate ion; GSH, glutathione; GS-SG, glutathione disulfide; KefF, KefC, glutathione-regulated potassium-efflux system; Oye, old yellow enzyme; PPP, pentose phosphate; protein-SH, protein with reduced cysteine; protein-S-SA, S-thioallylated protein; TCA cycle, Kreb's cycle; Trx, thioredoxin.
Resistance-conferring clones contained a congruent set of eight genes in common and 16 genes in total (Fig 2 and Table 1). Because allicin is a redox toxin causing oxidative- and disulfide stress, it was interesting to observe that half of these genes were annotated with redox-related functions (Fig 2B). Moreover, these genes were reported in the literature in the context of oxidative- and disulfide stress responses (Table 1).

Transposon mutagenesis of the resistance-conferring clones indicated that the $d s b A, t r x$, Refc, and oye genes worked together, contributing incrementally to confer allicin resistance to a sensitive recipient. In contrast, the effect of a mutation in $a h p D$ alone was major, with transposon mutants showing a similar phenotype to the sensitive parent transformed with empty vector (Fig 4B). These results are consistent with a multicomponent mechanism of allicin resistance. Annotated genes coding for significantly similar peptides were absent in the Pf0-1 reference strain, suggesting an external origin in PfAR-1. This observation would explain why spontaneous mutation to gain of resistance upon allicin selection was not observed in axenic cultures of sensitive isolates under laboratory conditions.

The contribution of individual genes on the clones to the resistance phenotype was investigated by expressing them in highly susceptible Ps4612 cells. Expression of either ahpD or dsbA conferred a degree of allicin resistance almost as high as that conferred by the complete genomic clone (Fig 4C). In contrast, trx or oye expression had no obvious effect, although loss of function in transposon mutants caused an increase in allicin sensitivity (Fig 4B). This might indicate that the function of these genes depends on the function of another gene or genes from the genomic fragment, or that there are downstream effects of the Tn insertion. Overexpression lines for osmC and kefC were not recovered in Ps4612, most likely because of toxic effects. This may be due to the fact that the activity of KefC is normally tightly regulated by KefF and GSH, and an imbalance can lead to a toxic decrease in cellular pH and loss of potassium, which are important to maintain turgor and enable cell growth and division (Epstein, 2003).

PfAR-1 genome analysis revealed unique features compared with the Pf0-1 reference strain. Three large genomic regions, between 79 and $98 \mathrm{kbp}$ in size, with a lower $\mathrm{GC}$ content were identified ( $\triangle \% \mathrm{GC}$ 5-10\%). These were designated GI1, GI2, and GI3 and they contained repeat regions $R E 1, R E 2$, and $R E 3$, respectively, which encompassed the resistance-conferring clones (Fig $3 \mathrm{~B}-\mathrm{E}$ ). Thus, the genome analysis and the functional studies independently identified the same set of genes. That these genes had been obtained by HGT was strongly indicated by codon usage analysis, which revealed differences in RE1, RE2, and RE3 compared with the core PfAR-1 genome (Fig S1). Comparison with other Pseudomonas spp. suggested that the origin of the GIs was outside this genus. The HGT hypothesis was strongly supported by our phylogenetic analysis (Supplemental Data 1) and an independent in silico analysis using IslandViewer 4 (Fig S2). By current selection criteria regions RE1, RE2, and RE3, and most likely 
the complete $\mathrm{Gl} 1, \mathrm{Gl}$, and $\mathrm{Gl} 3$ regions, can reliably be considered to be bona fide Gls obtained by HGT. The preponderance of genes with redox-related functions in the REs fits well with the role in resistance against allicin. As previously noted, the presence of such large, widely spaced REs in the PfAR-1 genome infers a high selection pressure to maintain them. Presumably, the latter relates to the allicin resistance-conferring function of the genes in question.

Although the Gl-donor remains unknown, phylogenetic analysis identified similar syntenic regions to the REs from PfAR-1 in several other pseudomonads (Fig 5A). Thus, the garlic pathogen P. salomoni ICMP14252 has two copies of the syntenic region, and the welldescribed model pathogen P. syringae pv. tomato DC3000 has one copy. The syntenic regions have the set of 10 core genes in clones 1-7 of PfAR-1 (Fig 5A). Furthermore, the degree of allicin resistance correlates with the copy number. Isolates with multiple copies showed higher allicin resistance than those with only one or zero copies (Fig 5B). P. salomoni causes the café-au-lait disease on garlic (Gardan et al, 2002) and its high degree of allicin resistance corresponds well with its niche as a pathogen of garlic. One might expect that a pathogen like $P$. salomoni could be the origin of allicin resistance genes in PfAR-1, but according to our codon usage analysis, the allicin resistance regions in $P$. salomini are quite distinct from the remainder of the genome and, therefore, were also likely obtained by HGT (Figs S1, S4, and Supplemental Data 1). Pst DC3000 is a model pathogen with a fully sequenced genome (Buell et al, 2003) that is pathogenic on tomato and on the model organism A. thaliana (Xin \& $\mathrm{He}, 2013)$. To the best of our knowledge, the genes and their function in allicin resistance have not been described before in this wellstudied strain. Our experiments suggest that the resistance conferred by the core region is specific to allicin-type oxidative stress and did not detectably increase resistance against other oxidants such as $\mathrm{H}_{2} \mathrm{O}_{2}, \mathrm{CHPO}$, or NEM (Fig 1C). Nevertheless, oxidative stress has manifold causes, and some genes in the syntenic region may help to counter the manifold aspects of other forms of oxidative stress under some conditions. Thus, the oxidative burst in plants is a general defense response to avirulent pathogens (Lamb \& Dixon, 1997). In this regard, it was reported that a transposon insertion in dsbA from the core genome of Pst DC3000 led to decreased virulence of Pst DC3000 on A. thaliana and on tomato (Kloek et al, 2000). Based on this study, it seems that the remaining $d s b A$ copy from the syntenic region of PSt DC3000 was not sufficient to functionally complement the loss of the $d s b A$ in the core genome, perhaps indicating a gene-dosage effect or subtly different functions between the two genes. It is intriguing to speculate that the syntenic region might help overcome the oxidative burst associated with plant defense, as well as protecting against more specifically redox-active sulfur-containing plant defense substances such as allicin, and it would be interesting to see if loss of syntenic genes other than dsbA in Pst DC3000 also leads to a reduction of virulence. Moreover, a recent study reported plasmid-born onion virulence regions in Pantoea ananatis strains that are pathogenic on onion (Stice et al, 2018, 2020 Preprint). The OVRA region contained a subset of genes that we describe in our present study as allicin resistance genes. More specifically, dsbA, which was annotated in P. ananatis OVRA as "isomerase," oye (as alkene reductase), trx, ahpD (annotated as alkylhydroperoxidase), glutathione disulfide reductase, sdr, and osmC, were all present. Although onion does not produce allicin, upon damage, it accumulates small amounts of other thiosulfinates and other sulfur-containing redox-active compounds which may be involved in defense (Block et al, 1992; Lawson et al, 1991b; Imai et al, 2002; Block, 2010). Nevertheless, there are several plant-pathogenic bacteria, for example, the bean pathogen $P$. syringae 1448A, which have no equivalent syntenic region but are successful plant pathogens in their own right. Therefore, there is clearly no absolute requirement for the syntenic region to enable colonization of plants as a habitat per se. In this regard, it should be noted that a comprehensive genomic analysis of plant-associated bacteria to identify protein domains associated with adaptation to growth in or on plants showed that seven of the 10 genes we identified in the syntenic region contained plant-associated domains as described by the authors (Levy et al, 2018). A list of pseudomonads with syntenic regions similar to those in PfAR-1 is shown in Table S2.

Allicin targets inter alia the GSH pool in plants, and GSH metabolism has been shown to be important in the resistance of bacteria, yeast, and A. thaliana to allicin (Gruhlke et al, 2010; Müller et al, 2016; Leontiev et al, 2018). In the work reported here, we show that PfAR-1 has three copies of the glutathione reductase (gor) gene, one copy each on RE1 and RE2, but outside the core region represented in clones $1-8$, and one copy in the core genome. This is quite remarkable because bacteria normally have only one gor gene. Exceptions, such as Pst DC3000 and P. salomoni ICMP14252, have an additional gor gene that was also very likely obtained by HGT as in PfAR-1. We demonstrated that the high gor copy number in PfAR-1 correlated with a twofold higher basal Gor enzyme activity compared with Pf0-1 with only one copy of gor (Fig S3). The importance of Gor activity for tolerance to allicin was shown by the enhanced sensitivity of an E. coli $\Delta$ gor knockout and the complementation of this phenotype by gor 1 from PfAR-1 (Fig 4D). Gor recycles oxidized glutathione (GSSG) to GSH. GSH protects cells from oxidative stress, either by direct reaction with pro-oxidants such as allicin, thus scavenging their oxidative capacity (Fig 6), or by serving as an electron donor for detoxifying enzymes such as glutathione peroxidase and glutaredoxins (Meister \& Anderson, 1983). It was shown that allicin treatment leads to oxidation of GSH to GSSG in yeast (Gruhlke et al, 2010) and to the formation of S-allylmercaptoglutathione (GSSA) (Horn et al, 2018). In yeast, both GSSA and GSSG are reduced by Gor to release GSH (Horn et al, 2018). Gram-positive bacteria, such as Staphylococcus aureus, have bacillothiol rather than GSH and in an independent investigation, we showed that the bacillothiol reductase YpdA, which is the functional equivalent of Gor, reduced S-allylated bacillothiol (BSSA). YpdA was important for the resistance of Staphylococcus to allicin (Loi et al, 2019). Furthermore, GSH negatively regulates the activity of KefC, but GSH conjugates stimulate KefC activity via Keff (Ferguson et al, 1997; Miller et al, 2000) (Fig 6). Thus, GSH inhibits $\mathrm{K}^{+}$efflux and E. coli $\Delta$ gsh mutants lose $\mathrm{K}^{+}$ions similarly to cells stressed with electrophiles such as NEM (Meury \& Kepes, 1982; Elmore et al, 1990). KefC activity acidifies the cytoplasm and has been reported to protect against oxidative stress caused by electrophiles such as NEM and methylglyoxal, presumably because the lowered pH works against thiolate ion formation (Ferguson et al, 1993, 1995, 1996, 1997; Poole, 2015). KefC activation could be expected to protect against oxidative stress caused by the electrophile allicin in the same way (Fig 6). Thus, some of the genes in the core fragment might be expected to help bacteria to be less sensitive to other oxidants. However, this effect was apparently not major enough to be 
observed in the tests documented in Fig $1 \mathrm{C}$, where only a reduced sensitivity to allicin-type stress was clearly observed.

Gor uses NADPH as a reductant and the pentose phosphate pathway (PPP) is the major source for NADPH in most cells. It has been shown that yeast mutants compromised in the $\mathrm{NADPH}$-producing steps of the PPP are hypersensitive to allicin (Leontiev et al, 2018). Because PfAR-1 lacks the 6-phospho-fructokinase gene necessary for glycolysis, it depends on the Entner-Doudoroff Pathway (EDP) to metabolize glucose to pyruvate, and this yields NADPH in addition to $\mathrm{NADH}$. Thus, the EDP confers an advantage during oxidative stress by providing an additional source of NADPH for Gor in addition to that from the PPP (Conway, 1992). It was shown for Pseudomonas putida that key enzymes of the EDP are up-regulated upon oxidative stress (Kim et al, 2008). NADPH is also used as reducing equivalents by antioxidative enzymes such as Oye-dehydrogenases. Moreover, in Mycobacterium tuberculosis, the AhpD enzyme depends on $\mathrm{NADH}$ consumption (Bryk et al, 2002), and thus, PfAR-1 could be able to tap into two pools of reducing equivalents, both NADPH and NADH, to defend against allicin stress (Fig 6).

Disulfide bond protein A (DsbA) is located in the periplasm in $E$. coli (Shouldice et al, 2011), and based on its protein domain content, in PfAR-1 DsbA might act as disulfide isomerase or as a chaperone (Fig 6). In E. coli, a part of the Dsb system is supported via thioredoxin-reducing equivalents from the cytosol (Trx) (Katzen \& Beckwith, 2000). The extra Trx copies in PfAR-1 might be important in this regard during allicin stress. How alkylhydroperoxidase D (AhpD) might protect PfAR-1 against allicin stress to such a high degree is so far unclear. Possibly, as in M. tuberculosis, it might act by using $\mathrm{NADH}$ to reduce oxidized molecules arising from oxidative stress (Bryk et al, 2002) caused by allicin (Fig 6).

Taken together, our data reinforce the central importance of GSH metabolism and redox enzymes in the resistance of cells to the electrophilic thiol reagent allicin and identify specific genes important for the multicomponent resistance mechanism. The maintenance of multiple copies of resistance genes, obtained by HGT, probably facilitates exploitation of the garlic ecological niche by PfAR-1 in competition with other bacteria.

\section{Materials and Methods}

Additional information about bacterial strains, plasmids, and primers are given in Tables S3-S5.

\section{Cultivation methods and media}

E. coli was routinely cultivated at $37^{\circ} \mathrm{C}$ in $2 \times Y T$ medium (Sambrook \& Russel, 2001).

Pseudomonads were routinely cultivated at $28^{\circ} \mathrm{C}$ in King's B medium (King et al, 1954). In contrast to the original recipe, $\mathrm{MgSO}_{4}$ was left out of the King's B medium in this study.

M9JB medium was developed during this study for the cultivation of Pseudomonas for reduced slime production. This defined medium is based on M9 salts (Maniatis, 1982) with glycerol as carbon source $(1.25 \%$ wt/vol). In addition, $1 \times$ Nitsch vitamin mixture (product N0410; Duchefa Biochemie) was added to complement for E. coli auxotrophies and
$3 \times$ complete supplement mix (product DCS0019; Formedium) to enrich the media for amino acids (except cysteine) to improve doubling time.

\section{Inhibition zone assays}

Bacteria were freshly grown from an optical density at $600 \mathrm{~nm}\left(\mathrm{OD}_{600}\right)$ of 0.05 to $\mathrm{OD}_{600}=0.2-0.3$. Bacteria-seeded agar was prepared by dispersing $300 \mu \mathrm{l}$ of liquid culture in $20 \mathrm{ml} 50^{\circ} \mathrm{C}$ warm agar medium and pouring immediately into Petri dishes. A surface lawn of bacteria was prepared by spreading $125 \mu \mathrm{l}$ of an $\mathrm{OD}_{600}=1.0$ culture onto $20 \mathrm{ml}$ of solidified agar in a Petri plate. Bacteria were spread over the surface with glass beads $(\phi=3 \mathrm{~mm})$ by gentle shaking. Wells $(\phi=0.6$ $\mathrm{cm}$ ) were punched out of the solidified agar with a cork borer to apply the test solution. Plates were then incubated overnight.

\section{Streak tests}

A single bacterial colony was picked and suspended in the liquid medium, then streaked away from a central well $(\phi=0.6 \mathrm{~cm})$ in 20 $\mathrm{ml}$ of solid medium in a Petri plate. Test solutions were pipetted into the central well.

\section{Drop tests}

Overnight E. coli suspension cultures were adjusted to $\mathrm{OD}_{600}=1.0$ and $10^{\mathrm{n}}$ dilution series to $\mathrm{OD}_{600}=10^{-5}$ were prepared. Aliquots $(5 \mu \mathrm{l})$ of each dilution were dropped on solid media $(2 \times Y \mathrm{Y})$ containing different amounts of allicin. Plates were incubated at $37^{\circ} \mathrm{C}$ overnight.

\section{Chemical synthesis of allicin}

Chemical synthesis of allicin was performed as described previously, with the exception that the allicin was not dried with $\mathrm{MgSO}_{4}$ but directly dissolved in $\mathrm{H}_{2} \mathrm{O}$ and used without further column purification. Purity and quantity was checked via HPLC analysis (Gruhlke et al, 2010).

\section{Protocol for high-yield genomic DNA (gDNA) extraction from bacteria}

For preparing a gDNA library of PfAR-1, a protocol for high-yield DNA extraction was established based on Chen and Kuo (1993) and on Syn and Swarup (2000). A 50-ml bacterial culture was grown overnight in liquid medium in a 500-ml Erlenmeyer flask. Bacteria were harvested by centrifugation $\left(2,500 \mathrm{~g}\right.$ for $20 \mathrm{~min}$ at $4^{\circ} \mathrm{C}$ ) in a $50-\mathrm{ml}$ reaction tube. The cell pellet was suspended in $20 \mathrm{ml}$ of $1 \% \mathrm{NaCl}$ solution (wt/vol in double-distilled water $\left[\mathrm{H}_{2} \mathrm{O}_{\mathrm{dd}}\right]$ ) for the removal of bacterial exopolysaccharides. Therefore, the cells were vortexed vigorously in the $\mathrm{NaCl}$ solution and harvested again by centrifugation. For removal of $\mathrm{NaCl}$, the bacterial cells were washed twice with $50 \mathrm{ml} \mathrm{H}_{2} \mathrm{O}_{\text {dd }}$ by vigorous vortexing and harvesting by centrifugation. The cells were finally suspended in $40 \mathrm{ml} \mathrm{H} \mathrm{O}_{\text {dd }}$. The cell solution was distributed among 2 $\mathrm{ml}$ reaction tubes and harvested at $12,879 \mathrm{~g}$ for $3 \mathrm{~min}$ at $4^{\circ} \mathrm{C}$. Afterwards, the supernatant was removed to the last drop. The cell pellets were vortexed without addition of buffer to loosen the cells from each other, thereby increasing the available surface for the subsequent lysis step. Bacterial lysis was performed by addition of $1.36 \mathrm{ml}$ lysis buffer (40 mM TRIS-HCl, pH 7.8, 20 mM sodium acetate, 1 mM EDTA, and 
$1 \%$ SDS [wt/vol = $35 \mathrm{mM}]$ ) to each reaction tube and mixing by pipetting up and down. The tubes were then incubated for $60 \mathrm{~min}$ in a $50^{\circ} \mathrm{C}$ water bath for enhanced lysis and DNA yield. Then, $12 \mu \mathrm{l}$ of RNase I (10 $\mathrm{mg} / \mathrm{ml}$ ) were added to each reaction tube and incubated for $30 \mathrm{~min}$ at $37^{\circ} \mathrm{C}$. To precipitate cell debris and SDS, $476 \mu \mathrm{L} 5 \mathrm{M} \mathrm{NaCl}$ were added to each reaction tube and mixed gently. The cell debris and SDS were then separated from the remaining solution via centrifugation at 20,937g for $20 \mathrm{~min}$ at $4^{\circ} \mathrm{C}$.

For further purification, $1.6 \mathrm{ml}$ from the supernatant of each reaction tube was gathered in an autoclaved glass bottle. Afterwards, the bottle was filled up with dilution buffer ( $40 \mathrm{mM}$ TRIS- $\mathrm{HCl}$, $\mathrm{pH} 7.8,20 \mathrm{mM}$ sodium acetate, $1 \mathrm{mM}$ EDTA, and $150 \mathrm{mM} \mathrm{NaCl}$ ) to 200 $\mathrm{ml}$ for dilution. The bottle was placed on ice.

For phase extraction, $5 \mathrm{ml}$ of chloroform were added to $40 \mathrm{ml}$ centrifugation tubes. The tubes were then filled up with the DNA solution which were gathered previously in the glass bottle and inverted 50 times. The phases were separated by centrifugation at $21,000 \mathrm{~g}$ for $3 \mathrm{~min}$ at $4^{\circ} \mathrm{C}$. The supernatant was gathered in a new sterile glass bottle. These extraction steps were repeated for the whole DNA solution in the glass bottle until no interphase was visible any more.

For DNA precipitation, $25 \mathrm{ml}$ of phase-extracted DNA solution was added to 50-ml reaction tubes and mixed with $25 \mathrm{ml}$ isopropanol. Because the lysis buffer and the dilution buffer contained enough salt (not removed during former steps), no further salt addition was needed for precipitation. The DNA-isopropanol/solutions were stored at $-20^{\circ} \mathrm{C}$ until all the remaining solution was processed to this stage of this protocol.

The DNA was subsequently precipitated into the same tubes at $21,000 \mathrm{~g}$ for $15 \mathrm{~min}$ at $4^{\circ} \mathrm{C}$. The two DNA pellets were washed twice with $70 \%$ ethanol. Last droplets of ethanol were removed via a Pasteur pipette. DNA pellets were dissolved in $10 \mathrm{mM}$ of TRIS-HCl, pH 8. The DNA was then aliquoted and stored at $-20^{\circ} \mathrm{C}$.

\section{PfAR-1 genomic library construction}

gDNA was extracted as described and partially digested with Sau3AI FD (Thermo Fisher Scientific). Sau3AI FD was diluted 300-fold in 1× FastDigest buffer (Thermo Fisher Scientific) and was applied to the reaction mixture for a 3,000-fold enzyme dilution. Digested DNA was size-separated via agarose gel electrophoresis and fragments of $\sim 10$ kbp were extracted and purified using Zymoclean Large Fragment DNA Recovery Kit, subcloned in BamHI-digested pRU1097, and electroporated in E. coli K12 DH10B MegaX. Plasmid DNA of $14,000 \mathrm{E}$. coli transformant colonies was extracted, representing more than 99.99\% theoretical coverage of the PfAR-1 genome.

\section{Transposon mutagenesis of genomic clone 1}

Transposon mutagenesis of PfAR-1 genomic clones on pRU1097 was performed in the Ps4612 background. Briefly, pSCR001 carrying transposon IS- $\Omega-\mathrm{km} /$ hah was transferred from E. coli S17 via biparental mating to Ps4612, and transconjugants were selected on gentamycin and kanamycin. Because pSCR001 cannot replicate in Ps4612, plasmid isolation from the transconjugants yields a Tn-carrying pRU1097 population, which was transformed in E. coli MegaX DH10B. Plasmid DNA of more than 10,000 Ps4612 genomic clone 1 transconjugants was extracted and electroporated in E. coli K12 DH10B MegaX to construct a library of Tn-carrying genomic clone 1.

\section{PCR applications and DNA cloning}

All DNA cloning steps in this work were based on enzymatic restriction and sticky end (or blunt end) DNA ligation with T4-DNA ligase from Thermo Fisher Scientific, except the construction of pJABO5 and the subsequent cloning of gor genes (see below). The necessary restriction sites for PCR fragments were introduced during PCR via primer overhangs if not already present in the DNA template.

For all PCR applications, the Phusion High-Fidelity PCR Master Mix (Thermo Fisher Scientific) was used according to the user manual.

\section{Construction of the broad host range expression vector pJABO}

Linearized pRU1097 was amplified via PCR with primers P163 and P174, thus adding ApaLI and Xhol restriction sites at the ends. The promoter from the neomycin phosphotransferase gene from pJP2neo was amplified with the primers P160 and P159, thus adding the restriction sites Nhel, Pvul, and Xhol upstream and ApaLI downstream of the promoter, respectively. Both the above PCR products were digested with ApaLI and Xhol and ligated together to give the pRU1097+Neo promoter intermediate.

Next, the multiple cloning site (MCS) from pBluescript I KS (-) was amplified with the primers P161 and P162, thus adding the restriction sites Nhel and Pvul After restriction with Pvul and Nhel, this was ligated with pRU1097+Neo promoter to give pRU1097+Neo+MCS.

The Notl restriction site in the mobilization gene (Mob) from pRU1097+Neo+MCS was removed by whole vector amplification using the primers P183 and P184 and subsequent blunt-end ligation. Primer P183 introduces a nucleotide exchange within the recognition sequence for Notl, resulting in the deletion of Notl without changing the encoded amino acid. The elimination of the restriction site was checked via restriction analysis and the constructed vector was analyzed by DNA sequencing. Sequencing showed that all components for gene expression except for the rrnB1 terminator sequence were present.

To restore the rrnB1 terminator somehow lost during the previous steps, the sequence was reamplified from pRU1097 with the primers P217 and P220, adding Sacl and Pvul restriction sites for subcloning.

The final vector construct pJABO was verified by restriction analysis and DNA sequencing of the promoter and the MCS as well as their flanking terminator sequences $T 4$ and rrnB1.

\section{Construction of the broad host range vector pJABO5 and cloning of PfAR-1 glutathione reductase gor1 gene for inducible expression in E. coli}

pJABO5, which was used for the expression of the PfAR-1 glutathione reductase in $E$. coli, was constructed by in vivo recombination in yeast. In comparison with pJABO, which was used for overexpression, pJABO5 was designed for induced gene expression based on the inducible lac promoter from E. coli.

pRU1097 was digested overnight with Xbal and Sacl, thereby removing GFP from pRU1097. Next, yeast $2 \mu$ ori and the URA3 selection marker were amplified from pRS426 via PCR using the primers P449 and P506. The lac promoter was amplified from E. coli MG1655 gDNA with primers P488 and P507, and the lacZ fragment was amplified from pBluescript I KS (-) using the primers P489 and P490. The vector 
backbone fragment of pRU1097 and the PCR products were transformed in Saccharomyces cerevisiae BY4742 as described in Jansen et al (2005). The vector was extracted from yeast by alkaline lysis and retransformed into E. coli for amplification.

For cloning of PfAR-1 glutathione reductase 1, gor1 had to be amplified via a nested PCR because the different glutathione reductases within the core genome and the horizontally transferred regions were too similar for separate, one-step amplification. Thus, the first PCR amplicon from PfAR-1 gDNA was generated with the primers P323 and P324 and used as a template for the amplification of PfAR-1 gor1 with the primers P524 and P525. The final product was cloned in pJABO5 by in vivo recombination in yeast (Jansen et al, 2005). pJABO5 was digested with BamHI and LacZ $\alpha$ was replaced by PfAR-1 gor1. The recombinant vector was isolated from yeast and directly transformed in E. coli BW25113 wild type or E. coli BW25113 $\Delta$ gor. The presence of the subcloned gor1 was verified by PCR using the primers P195 and P491.

\section{Protein extraction and glutathione reductase activity assay}

Pseudomonads were grown overnight in liquid M9JB medium to decrease slime production. Crude bacterial cell lysate was prepared from bacteria by vortexing with glass beads. Glutathione reductase activity assay was performed as described.

\section{Glutathione disulfide reductase enzyme assay}

For glutathione reductase activity assays, the cells were grown overnight at $28^{\circ} \mathrm{C}$ in liquid M9JB medium. Cells from $20 \mathrm{ml}$ overnight culture were harvested by centrifugation $(3,000 \mathrm{~g}$ at room temperature) and they were resuspended in $1 \mathrm{ml}$ phosphate buffer (143 $\mathrm{mM}$ Na-phosphate containing $6.2 \mathrm{mM}$ EDTA, pH 7.5). Bacteria were lysed mechanically by vortexing with $1-\mathrm{mm}$ glass beads three times for $1 \mathrm{~min}$ on ice. Cell debris were removed by centrifugation at $21,000 \mathrm{~g}$ for $1 \mathrm{~min}$ at room temperature.

Glutathione reductase activity was measured in a glutathione reductase recycling assay (Horn et al, 2018) modified to conditions showing linear dependency of the reaction velocity for enzyme amount, that is, not substrate-limited. Absorption was followed over $10 \mathrm{~min}$ at $412 \mathrm{~nm}$ using a spectrophotometer (DU800; Beckman Coulter $\mathrm{GmbH}$ ). Enzyme activity was calculated assuming a molar extinction coefficient of TNB of $13,600 \mathrm{M}^{-1} \cdot \mathrm{cm}^{-1}$ (Ellman, 1959). For calculation of specific enzyme activity, protein content of the sample was measured using the Bradford method (Bradford, 1976).

\section{Genome sequencing of PfAR-1}

PfAR-1 was grown in KB medium in a rotary shaker at $200 \mathrm{rpm}$ and $28^{\circ} \mathrm{C}$ overnight. For DNA extraction, $15 \mathrm{ml}$ of overnight culture was washed three times in 1×TE with $50 \mathrm{mM}$ EDTA by repeated pelleting at 5,000 $\mathrm{g}$ and resuspension by vortexing. The subsequent cell lysis was performed as described by Sambrook and Russel (2001) for Gram-negative bacteria. From this material, three Illumina pairedend libraries were created and run multiplexed in conjunction with other samples, twice as $2 \times 100$ paired-end runs on a HiSeq 2000, and once as a $2 \times 311$-bp paired-end run on a MiSeq. The resulting data were filtered by Trimmomatic V0.32 (Bolger et al, 2014) and assembled using SPAdes V3.5.0 (Bankevich et al, 2012). The resulting assembly was largely complete, with a total size of $6.3 \mathrm{Mbp}$, but it was still relatively fragmented with 40 scaffolds of $1 \mathrm{kbp}$ or larger and an N50 of $370 \mathrm{kbp}$.

To fully resolve the genome into one contig, two additional long read datasets were generated on the Pacific Biosciences RS-II platform. For DNA extraction, $15 \mathrm{ml}$ of overnight culture were washed three times in 1×TE with $50 \mathrm{mM}$ EDTA by repeated pelleting at 5,000 g and resuspension by vortexing. The subsequent cell lysis was performed as described in Sambrook and Russel (2001) for Gram-negative bacteria. Further depletion of contaminating polysaccharides was achieved by application of the Pacific Biosciences protocol (Pacific Biosciences, 2019) for gDNA cleanup. The final DNA was eluted in RNase-free water and quality was determined using NanoDrop for purity and Qubit for quantification. Sequencing was performed by GATC Biotech AG. The resulting two datasets, combined with the Illumina datasets described above, were then assembled, using SPAdes 3.5.0, yielding a single contig sequence of $\sim 6.26 \mathrm{Mbp}$.

Self-alignment of this contig revealed that 9,642-bp sequence was duplicated on each end which was then removed from one end. To simplify cross-genome comparisons, this sequence was aligned against the $P f 0-1$ reference sequence, and oriented to match, resulting in the 6,251,798-bp PfAR-1 assembly. The completed genome was then submitted to the RAST webserver (Aziz et al, 2008; Overbeek et al, 2014; Brettin et al, 2015) for automatic structural and functional annotation.

\section{In silico analysis of the PfAR-1 genome}

The low-GC regions identified in the PfAR-1 genome were initially compared manually by cross-referencing the functional annotation of genes. This revealed a list of genes from each region which have a potentially common origin. After removing low-confidence protein annotations, which were both unique to a single region and lacking a definitive functional annotation, namely, two hypothetical proteins, the remaining genes were manually reconciled into a putative ancestral arrangement of 26 genes.

\section{Comparison of putative HGT regions across the Pseudomonas genus}

A set of bait genes was created based on the putative 26-gene ancestral arrangement described above. Because these 26 groups were generally represented in more than one region, the set comprised 57 sequences in total. All available Pseudomonas sequences, comprising 215 complete genomes and 3,132 draft genomes, were downloaded from the Pseudomonas Genome Database Web site (https:/ /www.pseudomonas.com/) and queried for the bait sequences using BLAST. Similarity was calculated using a sliding window of 40 genes, and regions which exceeded a normalized bit-score total of five were selected.

\section{Interspecies codon analysis}

Synonymous codon usage statistics were calculated for the full PfAR-1 genome, the three putative HGT regions, the 3,347 other available Pseudomonas genomes, and eight representative non-Pseudomonas Gammaproteobacteria (A. baumannii AC29, Alkanindiges illinoisensis, A. vinelandii DJ, E. coli K12 MG1655, Moraxella catarrhalis, Perlucidibaca piscinae, $R$. rubra, and Ventosimonas gracilis). After removing methionine 
and tryptophan, which have only one codon, the remaining codons were analyzed using principal component analysis.

\section{Gene window codon analysis of PfAR-1, Pf0-1, Pst DC3000, and P. salomoni ICMP 14252}

From the 3,347 publicly available genomes, three were selected, in addition to PfAR-1, for assessment of local codon usage using a 10-gene sliding window approach. These three genomes were Pf0-1, as the reference Pseudomonas strain closely related to PfAR-1, although lacking any putative HGT region; Pst DC3000, a well-studied plant pathogen, which contained one putative HGT region; and $P$. salomoni ICMP14252, a garlic pathogen which contains two putative HGT regions.

\section{Phylogenetic comparison of whole genome versus RE-like sequences}

Whole-genome phylogenetic analysis was performed using OrthoFinder (Emms \& Kelly, 2015; version 1.1.8, https://github.com/ davidemms/OrthoFinder/releases/tag/1.1.8) to place the newly sequenced PfAR-1 genome in its phylogenetic context, using a subset of 280 Pseudomonas genomes supplemented by four more distant genomes downloaded from National Center for Biotechnology Information GenBank, namely, A. vinelandii DJ, A. baumannii AC29, E. coli K12 MG1655, and B. cenocepacia 2315 which served as an outgroup. The 280 Pseudomonas genome subset consisted of a) all 215 complete genomes, b) the draft genomes showing a substantial hit against the putative-HGT gene set, as described above, and c) nine Pseudomonas genomes with unusual codon usage (P. lutea, P. luteola, P. sp HPB0071, P. sp FeS53a, P. zeshuii, P. hussainii JCM, P. hussainii MB3, P. caeni, and P. endophytica).

In a second analysis, the three putative-HGT from PfAR-1 were compared against the corresponding regions from other Pseudomonas genomes, identified as described above. For this analysis, the sequences from each GI region were re-ordered according to the best match against the 26 bait group sequences, concatenated to form a single pseudosequence and aligned using MAFFT (version 7, [Katoh \& Standley, 2013]). The resulting multiple alignment was accessed using "fitch" from Phylip (version 3.69) and the resulting trees were visualized using FigTree (version 1.4.3, https://github.com/rambaut/figtree/releases/tag/v1.4.3).

\section{IslandViewer analysis}

For independent confirmation of the HGT analysis, the PfAR-1 genome was submitted to the IslandViewer 4 (Bertelli et al, 2017) Web site, for assessment regarding HGT events.

\section{Additional annotation of genomic repeat regions}

Gaps in the annotation of genomic repeats with putative horizontal origin indicated incomplete annotation, also implicated by a low gene density (1 gene per 1.3-1.6 kbp), which is expected to be one gene per 1 $\mathrm{kbp}$ in bacterial genomes (Koonin \& Wolf, 2008). Regions were submitted individually without the remaining genome sequence to the RAST webserver, thereby closing annotational gaps (1 gene per 0.90 $\mathrm{kbp}$ in average). Remaining DNA regions without annotation were manually curated using National Center for Biotechnology Information open reading frame finder and BLASTp.

\section{Dot plot and \%GC content analysis}

For dot plot analysis and \%GC content analysis and comparison, Genome Pair Rapid Dotter (GEPARD, [Krumsiek et al, 2007]), Artemis Comparison Tool (Carver et al, 2005), and UGENE (Okonechnikov et al, 2012) were used, respectively.

\section{Congruent set of genes and copy number analysis}

Analysis was performed by batch translation of the coding sequences of the PfAR-1 genomic repeats into peptide sequences using coderet from the emboss suite (Rice et al, 2000) and compared these against all other peptide sequences from the genomic repeats and the remaining genome, respectively. Peptides with a minimal peptide length of $\geq 100$ amino acids were compared using BLASTp combined with the graphical user interface visual blast (Mele, 2016). Significantly similar sequences were defined by a minimal sequence similarity of $\geq 25 \%$ and with an E-value $\leq 0.0001$.

\section{Data Availability}

The PfAR-1 genome sequence is available at European Molecular Biology Laboratory - European Bioinformatics Institute under project PRJEB34663.

\section{Supplementary Information}

Supplementary Information is available at https://doi.org/10.26508/lsa. 202000670.

\section{Acknowledgements}

Nikolaus Schlaich and Jürgen Prell are thanked for helpful discussions and Ulrike Noll for proof-reading the manuscript. Financial support from the Rheinisch-Westfälische Technische Hochschule Aachen University (J Borlinghaus, AJ Slusarenko, MCH Gruhlke) is gratefully acknowledged. J Borlinghaus was supported by an RFwN PhD stipendium and A Bolger by Bundesministerium für Bildung und Forschung (BMBF) grant 031A536. This research did not receive any specific grant from funding agencies in the public, commercial, or not-for-profit sectors.

\section{Author Contributions}

J Borlinghaus: conceptualization, investigation, visualization, methodology, and writing-original draft, review, and editing.

A Bolger: conceptualization, data curation, software, formal analysis, investigation, methodology, and writing-original draft, review, and editing.

C Schier: investigation and methodology.

A Vogel: investigation and methodology.

B Usadel: writing-review and editing.

MCH Gruhlke: methodology and writing-original draft, review, and editing. 
AJ Slusarenko: conceptualization, resources, supervision, visualization, project administration, and writing-original draft, review, and editing.

\section{Conflict of Interest Statement}

The authors declare that they have no conflict of interest.

\section{References}

Aziz RK, Bartels D, Best AA, Dejongh M, Disz T, Edwards RA, Formsma K, Gerdes S, Glass EM, Kubal M, et al (2008) The RAST server: Rapid annotations using subsystems technology. BMC Genomics 9: 75. doi:10.1186/1471-2164-9-75

Baba T, Ara T, Hasegawa M, Takai Y, Okumura Y, Baba M, Datsenko KA, Tomita M, Wanner BL, Mori H (2006) Construction of Escherichia coli K-12 inframe, single-gene knockout mutants: The Keio collection. Mol Syst Biol 2: 2006.0008. doi:10.1038/msb4100050

Bankevich A, Nurk S, Antipov D, Gurevich AA, Dvorkin M, Kulikov AS, Lesin VM, Nikolenko SI, Pham S, Prjibelski AD, et al (2012) SPAdes: A new genome assembly algorithm and its applications to single-cell sequencing. J Comp Biol 19: 455-477. doi:10.1089/cmb.2012.0021

Bardwell JCA, McGovern K, Beckwith J (1991) Identification of a protein required for disulfide bond formation in vivo. Cell 67: 581-589. doi:10.1016/0092-8674(91)90532-4

Bertelli C, Laird MR, Williams KP, Simon Fraser University Research Computing Group, Lau BY, Hoad G, Winsor GL, Brinkman FS (2017) IslandViewer 4: Expanded prediction of genomic islands for largerscale datasets. Nucleic Acids Res 45: W30-W35. doi:10.1093/nar/gkx343

Blattner FR, Plunkett G, Bloch CA, Perna NT, Burland V, Riley M, Collado-Vides J, Glasner JD, Rode CK, Mayhew GF, et al (1997) The complete genome sequence of Escherichia coli K-12. Science 277: 1453. doi:10.1126/ science.277.5331.1453

Block E (2010) Garlic and Other Alliums: The Lore and the Science. Cambridge, UK: The Royal Society of Chemistry. RSC Publishing. ISBN 10:1849731802.

Block E, Naganthan S, Putman D, Zhao SH (1992) Allium chemistry: HPLC analysis of thiosulfinates from onion, garlic, wild garlic (ramsoms), leek, scallion, shallot, elephant (great-headed) garlic, chive, and Chinese chive. Uniquely high allyl to methyl ratios in some garlic samples. J Agric Food Chem 40: 2418-2430. doi:10.1021/jf00024a017

Bolger AM, Lohse M, Usadel B (2014) Trimmomatic: A flexible trimmer for Illumina sequence data. Bioinformatics 30: 2114-2120. doi:10.1093/ bioinformatics/btu170

Borlinghaus J, Albrecht F, Gruhlke MCH, Nwachukwu ID, Slusarenko AJ (2014) Allicin: Chemistry and biological properties. Molecules 19: 12591-12618. doi:10.3390/molecules19081259

Boyer HW, Roulland-Dussoix D (1969) A complementation analysis of the restriction and modification of DNA in Escherichia coli. J Mol Biol 41: 459-472. doi:10.1016/0022-2836(69)90288-5

Bradford MM (1976) A rapid and sensitive method for the quantitation of microgram quantities of protein utilizing the principle of protein-dye binding. Anal Biochem 72: 248-254. doi:10.1016/0003-2697(76)90527-3

Brettin T, Davis J), Disz T, Edwards RA, Gerdes S, Olsen GJ, Olson R, Overbeek R, Parrello B, Pusch GD, et al (2015) RASTtk: A modular and extensible implementation of the RAST algorithm for building custom annotation pipelines and annotating batches of genomes. Sci Rep 5: 8365. doi:10.1038/srep08365

Bryk R, Lima CD, Erdjument-Bromage H, Tempst P, Nathan C (2002) Metabolic enzymes of mycobacteria linked to antioxidant defense by a thioredoxinlike protein. Science 295: 1073-1077. doi:10.1126/science.1067798

Buell CR, Joardar V, Lindeberg M, Selengut J, Paulsen IT, Gwinn ML, Dodson RJ, Deboy RT, Durkin AS, Kolonay JF, et al (2003) The complete genome sequence of the
Arabidopsis and tomato pathogen Pseudomonas syringae pv. tomato DC3000. Proc Natl Acad Sci U S A 100: 10181. doi:10.1073/pnas.1731982100

Burdon JJ, Thrall PH (2009) Coevolution of plants and their pathogens in natural habitats. Science 324: 755-756. doi:10.1126/science.1171663

Carver TJ, Rutherford KM, Berriman M, Rajandream MA, Barrell BG, Parkhill J (2005) ACT: The Artemis comparison tool. Bioinformatics 21: 3422-3423. doi:10.1093/bioinformatics/bti553

Cavallito CJ, Bailey JH (1944) Allicin, the antibacterial principle of Allium sativum. I. Isolation, physical properties and antibacterial action. J Am Chem Soc 66: 1950-1951. doi:10.1021/ja01239a048

Cavallito CJ, Buck JS, Suter CM (1944) Allicin, the antibacterial principle of Allium sativum. II. Determination of the chemical structure. J Am Chem Soc 66: 1952-1954. doi:10.1021/ja01239a049

Chen WP, Kuo TT (1993) A simple and rapid method for the preparation of gram-negative bacterial genomic DNA. Nucleic Acids Res 21: 2260. doi:10.1093/nar/21.9.2260

Chi BK, Huyen NTT, Loi VV, Gruhlke MCH, Schaffer M, Mäder U, Maaß S, Becher D, Bernhardt J, Arbach M, et al (2019) The disulfide stress response and protein S-thioallylation caused by allicin and diallyl polysulfanes in Bacillus subtilis as revealed by transcriptomics and proteomics. Antioxidants (Basel) 8: 605. doi:10.3390/antiox8120605

Conway T (1992) The Entner-Doudoroff pathway: History, physiology and molecular biology. FEMS Microbiol Lett 103: 1-28. doi:10.1111/j.15746968.1992.tb05822.x

Datsenko KA, Wanner BL (2000) One-step inactivation of chromosomal genes in Escherichia coli K-12 using PCR products. Proc Natl Acad Sci U S A 97: 6640. doi:10.1073/pnas.120163297

Douglas RM, Roberts JA, Munro AW, Ritchie GY, Lamb AJ, Booth IR (1991) The distribution of homologues of the Escherichia coli KefC $\mathrm{K}^{+}$-efflux system in other bacterial species. J Gen Microbiol 137: 1999-2005. doi:10.1099/00221287-137-8-1999

Elmore MJ, Lamb AJ, Ritchie GY, Douglas RM, Munro A, Gajewska A, Booth IR (1990) Activation potassium efflux from Escherichia coli by glutathione metabolites. Mol Microbiol 4: 405-412. doi:10.1111/j.1365-2958.1990.tb00607.x

Emms DM, Kelly S (2015) OrthoFinder: Solving fundamental biases in whole genome comparisons dramatically improves orthogroup inference accuracy. Genome Biol 16: 157. doi:10.1186/s13059-015-0721-2

Epstein W (2003) The roles and regulation of potassium in bacteria. Prog Nucleic Acid Res Mol Biol 75: 293-320. doi:10.1016/s0079-6603(03)75008-9

Ellman GL (1959) Tissue sulfhydryl groups. Arch Biochem Biophys 82: 70-77. doi:10.1016/0003-9861(59)90090-6

Ferguson GP, Chacko AD, Lee CH, Booth IR, Lee C (1996) The activity of the highaffinity $\mathrm{K}^{+}$uptake system $\mathrm{Kdp}$ sensitizes cells of Escherichia coli to methylglyoxal. J Bacteriol 178: 3957-3961. doi:10.1128/jb.178.13.3957-3961.1996

Ferguson GP, McLaggan D, Booth IR (1995) Potassium channel activation by glutathione-S-conjugates in Escherichia coli: Protection against methylglyoxal is mediated by cytoplasmic acidification. Mol Microbiol 17: 1025-1033. doi:10.1111/j.1365-2958.1995.mmi_17061025.x

Ferguson GP, Munro AW, Douglas RM, McLaggan D, Booth IR (1993) Activation of potassium channels during metabolite detoxification in Escherichia coli. Mol Microbiol 9: 1297-1303. doi:10.1111/j.1365-2958.1993.tb01259.x

Ferguson GP, Nikolaev Y, McLaggan D, Maclean M, Booth IR (1997) Survival during exposure to the electrophilic reagent $N$-ethylmaleimide in Escherichia coli: Role of KefB and KefC potassium channels. J Bacteriol 179: 1007-1012. doi:10.1128/jb.179.4.1007-1012.1997

Fitzpatrick TB, Amrhein N, Macheroux P (2003) Characterization of YqjM, an old yellow enzyme homolog from Bacillus subtilis involved in the oxidative stress response. J Biol Chem 278: 19891-19897. doi:10.1074/ jbc.M211778200

Gardan L, Bella P, Meyer JM, Christen R, Rott P, Achouak W, Samson R (2002) Pseudomonas salomonii sp. nov., pathogenic on garlic, and 
Pseudomonas palleroniana sp. nov., isolated from rice. Int I Syst Evol Microbiol 52: 2065-2074. doi:10.1099/00207713-52-6-2065

Giddens SR, Jackson RW, Moon CD, Jacobs MA, Zhang XX, Gehrig SM, Rainey PB (2007) Mutational activation of niche-specific genes provides insight into regulatory networks and bacterial function in a complex environment. Proc Natl Acad Sci U S A 104: 18247. doi:10.1073/pnas.0706739104

Gruhlke MCH, Antelmann H, Bernhardt J, Kloubert V, Rink L, Slusarenko AJ (2019) The human allicin-proteome: S-thioallylation of proteins by the garlic defence substance allicin and its biological effects. Free Radic Biol Med 131: 144-153. doi:10.1016/j.freeradbiomed.2018.11.022

Gruhlke MCH, Portz D, Stitz M, Anwar A, Schneider T, Jacob C, Schlaich NL, Slusarenko AJ (2010) Allicin disrupts the cell's electrochemical potential and induces apoptosis in yeast. Free Radic Biol Med 49: 1916-1924. doi:10.1016/j.freeradbiomed.2010.09.019

Gruhlke MCH, Schlembach I, Leontiev R, Uebachs A, Gollwitzer PUG, Weiss A, Delaunay A, Toledano M, Slusarenko AJ (2017) Yap1p, the central regulator of the $S$. cerevisiae oxidative stress response, is activated by allicin, a natural oxidant and defence substance of garlic. Free Radic Biol Med 108: 793-802. doi:10.1016/j.freeradbiomed.2017.05.004

Hanahan D (1983) Studies on transformation of Escherichia coli with plasmids. J Mol Biol 166: 557-580. doi:10.1016/s0022-2836(83)80284-8

Halliwell B, Gutteridge JMC (2015) Free Radicals in Biology and Medicine. Oxford: Oxford University Press.

Holmgren A (2000) Antioxidant function of thioredoxin and glutaredoxin systems. Antioxid Redox Signal 2: 811-820. doi:10.1089/ars.2000.2.4-811

Horn T, Bettray W, Slusarenko AJ, Gruhlke MCH (2018) S-allylmercaptoglutathione is a substrate for glutathione reductase (E.C. 1.8.1.7) from yeast (Saccharomyces cerevisiae). Antioxidants 7: 86. doi:10.3390/antiox7070086

Hsiao W, Wan I, Jones SJ, Brinkman FSL (2003) IslandPath: Aiding detection of genomic islands in prokaryotes. Bioinformatics 19: 418-420. doi:10.1093/bioinformatics/btg004

Imai S, Tsuge N, Tomotake M, Nagatome Y, Sawada H, Nagata T, Kumagai H (2002) An onion enzyme that makes the eyes water. Nature 419: 685. doi:10.1038/419685a

Jansen G, Wu C, Schade B, Thomas DY, Whiteway M (2005) Drag\&Drop cloning in yeast. Gene 344: 43-51. doi:10.1016/j.gene.2004.10.016

Joardar V, Lindeberg M, Jackson RW, Selengut J, Dodson R, Brinkac LM, Daugherty SC, DeBoy R, Durkin AS, Giglio MG, et al (2005) Wholegenome sequence analysis of Pseudomonas syringae pv. phaseolicola $1448 \mathrm{~A}$ reveals divergence among pathovars in genes involved in virulence and transposition. J Bacteriol 187: 6488-6498. doi:10.1128/JB.187.18.6488-6498.2005

Kamitani S, Akiyama Y, Ito K (1992) Identification and characterization of an Escherichia coli gene required for the formation of correctly folded alkaline phosphatase, a periplasmic enzyme. EMBO J 11: 57-62. doi:10.1002/j.1460-2075.1992.tb05027.x

Karunakaran R, Mauchline TH, Hosie AHF, Poole PS (2005) A family of promoter probe vectors incorporating autofluorescent and chromogenic reporter proteins for studying gene expression in gram-negative bacteria. Microbiology 151: 3249-3256. doi:10.1099/mic.0.28311-0

Katoh K, Standley DM (2013) MAFFT multiple sequence alignment software version 7: Improvements in performance and usability. Mol Biol Evol 30: 772-780. doi:10.1093/molbev/mst010

Katzen F, Beckwith J (2000) Transmembrane electron transfer by the membrane protein DsbD occurs via a disulfide bond cascade. Cell 103: 769-779. doi:10.1016/s0092-8674(00)00180-x

Kavanagh KL, Jörnvall H, Persson B, Oppermann U (2008) The SDR superfamily: Functional and structural diversity within a family of metabolic and regulatory enzymes. Cell Mol Life Sci 65: 3895-3906. doi:10.1007/s00018-008-8588-y

Khairnar NP, Joe M-H, Misra HS, Lim S-Y, Kim D-H (2013) FrnE, a cadmiuminducible protein in Deinococcus radiodurans, is characterized as a disulfide isomerase chaperon in vitro and for its role in oxidative stress tolerance in vivo. J Bacteriol 195: 2880-2886. doi:10.1128/JB.01503-12

Kim J, Jeon CO, Park W (2008) Dual regulation of zwf- 1 by both 2-keto-3-deoxy6-phosphogluconate and oxidative stress in Pseudomonas putida. Microbiology 154: 3905-3916. doi:10.1099/mic.0.2008/020362-0

King EO, Ward MK, Raney DE (1954) Two simple media for the demonstration of pyocyanin and fluorescin. J Lab Clin Med 44: 301-307. doi:10.2307/211788

Kloek AP, Brooks DM, Kunkel BN (2000) A dsbA mutant of Pseudomonas syringae exhibits reduced virulence and partial impairment of type III secretion. Mol Plant Pathol 1: 139-150. doi:10.1046/j.1364-3703.2000.00016.x

Koonin EV, Wolf YI (2008) Genomics of bacteria and archaea: The emerging dynamic view of the prokaryotic world. Nucleic Acids Res 36 : 6688-6719. doi:10.1093/nar/gkn668

Koshkin A, Nunn CM, Djordjevic S, Ortiz de Montellano PR (2003) The mechanism of Mycobacterium tuberculosis alkylhydroperoxidase AhpD as defined by mutagenesis, crystallography, and kinetics. J Biol Chem 278: 29502-29508. doi:10.1074/jbc.M303747200

Krumsiek J, Arnold R, Rattei T (2007) Gepard: A rapid and sensitive tool for creating dotplots on genome scale. Bioinformatics 23: 1026-1028. doi:10.1093/ bioinformatics/btm039

Lamb C, Dixon RA (1997) The oxidative burst IN plant disease resistance. Annu Rev Plant Physiol Plant Mol Biol 48: 251-275. doi:10.1146/annurev. arplant.48.1.251

Langille MG, Hsiao WW, Brinkman FS (2008) Evaluation of genomic island predictors using a comparative genomics approach. BMC Bioinformatics 9: 329. doi:10.1186/1471-2105-9-329

Lawson LD, Hughes BG (1992) Characterization of the formation of allicin and other thiosulfinates from garlic. Planta Med 58: 345-350. doi:10.1055/s-2006-961482

Lawson LD, Wang ZJ, Hughes BG (1991a) Identification and HPLC quantitation of the sulfides and dialk(en)yl thiosulfinates in commercial garlic products. Planta Med 57: 363-370. doi:10.1055/s-2006-960119

Lawson LD, Wang Z-YJ, Hughes BG (1991b) $\gamma$-glutamyl-S-alkylcysteines in garlic and other Allium spp.: Precursor of age-dependent trans-1-propenyl thiosulfinates. J Nat Prod 54: 436-444. doi:10.1021/np50074a014

Lee I, Ouk Kim Y, Park S-C, Chun J (2016) OrthoANI: An improved algorithm and software for calculating average nucleotide identity. Int I Syst Evol Microbiol 66: 1100-1103. doi:10.1099/ijsem.0.000760

Leontiev R, Hohaus N, Jacob C, Gruhlke MCH, Slusarenko AJ (2018) A comparison of the antibacterial and antifungal activities of thiosulfinate analogues of allicin. Sci Rep 8: 6763. doi:10.1038/s41598-018-25154-9

Lesniak J, Barton WA, Nikolov DB (2003) Structural and functional features of the Escherichia coli hydroperoxide resistance protein OsmC. Protein Sci 12: 2838-2843. doi:10.1110/ps.03375603

Levy A, Salas Gonzalez I, Mittelviefhaus M, Clingenpeel S, Herrera Paredes S, Miao J, Wang K, Devescovi G, Stillman K, Monteiro F, et al (2018) Genomic features of bacterial adaptation to plants. Nat Genet 50: 138-150. doi:10.1038/s41588-017-0012-9

Loi VV, Huyen NTT, Busche T, Tung QN, Gruhlke MCH, Kalinowski J, Bernhardt J, Slusarenko AJ, Antelmann H (2019) Staphylococcus aureus responds to allicin by global S-thioallylation: Role of the Brx/BSH/YpdA pathway and the disulfide reductase MerA to overcome allicin stress. Free Radic Biol Med 139: 55-69. doi:10.1016/j.freeradbiomed.2019.05.018

Lyngberg L, Healy J, Bartlett W, Miller S, Conway SJ, Booth IR, Rasmussen T (2011) KefF, regulatory subunit of the potassium efflux system KefC, shows quinone oxidoreductase activity. J Bacteriol 18: 4925-4932. doi:10.1128/JB.05272-11

MacLean RC, San Millan A (2019) The evolution of antibiotic resistance. Science 365: 1082. doi:10.1126/science.aax3879

Maniatis T (1982) Molecular Cloning: A Laboratory Manual, Maniatis T, Fritsch EF, Sambrook J. Cold Spring Harbor, NY: Cold Spring Harbor Laboratory.

Meister A, Anderson ME (1983) Glutathione. Annu Rev Biochem 52: 711-760. doi:10.1146/annurev.bi.52.070183.003431 
Mele G (2016) Visual blast. Smart eLab 8: 14-16. doi:10.30441/smart-elab.v8i0.192

Meury J, Kepes A (1982) Glutathione and the gated potassium channels of Escherichia coli. EMBO J 1: 339-343. doi:10.1002/j.14602075.1982.tb01171.x

Miller S, Ness LS, Wood CM, Fox BC, Booth IR (2000) Identification of an ancillary protein, YabF, required for activity of the KefC glutathionegated potassium efflux system in Escherichia coli. / Bacteriol 182: 6536-6540. doi:10.1128/jb.182.22.6536-6540.2000

Miron T, Rabinkov A, Mirelman D, Wilchek M, Weiner L (2000) The mode of action of allicin: Its ready permeability through phospholipid membranes may contribute to its biological activity. Biochim Biophys Acta 1463: 20-30. doi:10.1016/S0005-2736(99)00174-1

Müller A, Eller J, Albrecht F, Prochnow P, Kuhlmann K, Bandow JE, Slusarenko AJ, Leichert LIO (2016) Allicin induces thiol stress in bacteria through S-allylmercapto modification of protein cysteines. J Biol Chem 291: 11477-11490. doi:10.1074/jbc.M115.702308

Mumberg D, Müller R, Funk M (1995) Yeast vectors for the controlled expression of heterologous proteins in different genetic backgrounds. Gene 156: 119-122. doi:10.1016/0378-1119(95)00037-7

Munro AW, Ritchie GY, Lamb AJ, Douglas RM, Booth IR (1991) The cloning and DNA sequence of the gene for the glutathione-regulated potassiumefflux system KefC of Escherichia coli. Mol Microbiol 5: 607-616. doi:10.1111/j.1365-2958.1991.tb00731.x

Neidhardt FC, Curtiss R (1996) Escherichia Coli and Salmonella: Cellular and Molecular Biology. Washington, DC: ASM Press.

Okonechnikov K, Golosova O, Fursov M, UGENE team (2012) Unipro UGENE: A unified bioinformatics toolkit. Bioinformatics 28: 1166-1167. doi:10.1093/bioinformatics/bts091

Overbeek R, Olson R, Pusch GD, Olsen GJ, Davis JJ, Disz T, Edwards RA, Gerdes S, Parrello B, Shukla M, et al (2014) The SEED and the rapid annotation of microbial genomes using subsystems technology (RAST). Nucleic Acids Res 42: D206-D214. doi:10.1093/nar/gkt1226

Pacific Biosciences (2019) Guidelines for using a salt: Chloroform wash to clean up gDNA. https://www.pacb.com/wp-content/uploads/2015/ 09/Shared-Protocol-Guidelines-for-Using-a-Salt-Chloroform-Washto-Clean-Up-gDNA.pdf.

Poole LB (2015) The basics of thiols and cysteines in redox biology and chemistry. Free Radic Biol Med 80: 148-157. doi:10.1016/ j.freeradbiomed.2014.11.013

Prell J, Boesten B, Poole P, Priefer UB (2002) The Rhizobium leguminosarum bv. viciae VF39 $\gamma$-aminobutyrate (GABA) aminotransferase gene (gabT) is induced by GABA and highly expressed in bacteroids. Microbiology 148: 615-623. doi:10.1099/00221287-148-2-615

Ramos JL, Martínez-Bueno M, Molina-Henares AJ, Terán W, Watanabe K, Zhang X, Gallegos MT, Brennan R, Tobes R (2005) The TetR family of transcriptional repressors. Microbiol Mol Biol Rev 69: 326-356. doi:10.1128/MMBR.69.2.326-356.2005

Reiter J, Levina N, van der Linden M, Gruhlke M, Martin C, Slusarenko AJ (2017) Diallylthiosulfinate (allicin), a volatile antimicrobial from garlic (Allium sativum), kills human lung pathogenic bacteria, including MDR strains, as a vapor. Molecules 22: 1711. doi:10.3390/ molecules22101711

Rice P, Longden I, Bleasby A (2000) EMBOSS: The European molecular biology open software suite. Trends Genet 16: 276-277. doi:10.1016/s01689525(00)02024-2

Rocha EPC (2003) DNA repeats lead to the accelerated loss of gene order in bacteria. Trends Genet 19: 600-603. doi:10.1016/j.tig.2003.09.011

Sambrook J, Russel DW (2001) Molecular Cloning. New York: Cold Spring Harbor Laboratory Press.

Shouldice SR, Heras B, Walden PM, Totsika M, Schembri MA, Martin JL (2011) Structure and function of DsbA, a key bacterial oxidative folding catalyst. Antioxid Redox Signal 14:1729-1760. doi:10.1089/ars.2010.3344
Simon R, Priefer U, Pühler A (1983) A broad host range mobilization system for in vivo genetic engineering: Transposon mutagenesis in gram negative bacteria. Bio/Technology 1: 784. doi:10.1038/nbt1183-784

Smeets K, Van Damme EJ, Van Leuven F, Peumans WJ (1997) Isolation and characterization of lectins and lectin-alliinase complexes from bulbs of garlic (Allium sativum) and ramsons (Allium ursinum). Glycoconj J 14: 331-343. doi:10.1023/a:1018570628180

Soucy SM, Huang J, Gogarten JP (2015) Horizontal gene transfer: Building the web of life. Nat Rev Genet 16: 472-482. doi:10.1038/nrg3962

Stice SP, Stumpf SD, Gitaitis RD, Kvitko BH, Dutta B (2018) Pantoea ananatis genetic diversity analysis reveals limited genomic diversity as well as accessory genes correlated with onion pathogenicity. Front Microbiol 9: 184. doi:10.3389/fmicb.2018.00184

Stice SP, Thao KK, Khang CH, Baltrus DA, Dutta B, Kvitko BH (2020) Pantoea ananatis defeats Allium chemical defenses with a plasmid-borne virulence gene cluster. BioRxiv. doi:10.1101/2020.02.12.945675 (Preprint posted February 13, 2020)

Stott K, Saito K, Thiele DJ, Massey V (1993) Old yellow enzyme. The discovery of multiple isozymes and a family of related proteins. I Biol Chem 268: 6097-6106.

Syn CKC, Swarup S (2000) A scalable protocol for the isolation of large-sized genomic DNA within an hour from several bacteria. Anal Biochem 278: 86-90. doi:10.1006/abio.1999.4410

Trotter EW, Collinson EJ, Dawes IW, Grant CM (2006) Old yellow enzymes protect against acrolein toxicity in the yeast Saccharomyces cerevisiae. Appl Environ Microbiol 72: 4885-4892. doi:10.1128/ aem.00526-06

Van Damme EJM, Smeets K, Torrekens S, Van Leuven F, Peumans WJ (1992) Isolation and characterization of alliinase CDNA clones from garlic (Allium sativum L.) and related species. Eur J Biochem 209: 751-757. doi:10.1111/j.1432-1033.1992.tb17344.X

Vaz ADN, Chakraborty S, Massey V (1995) Old yellow enzyme: Aromatization of cyclic enones and the mechanism of a novel dismutation reaction. Biochemistry 34: 4246-4256. doi:10.1021/bi00013a014

Waack S, Keller O, Asper R, Brodag T, Damm C, Fricke WF, Surovcik K, Meinicke $P$, Merkl R (2006) Score-based prediction of genomic islands in prokaryotic genomes using hidden Markov models. BMC Bioinformatics 7: 142. doi:10.1186/1471-2105-7-142

Whitman CP (2002) The 4-oxalocrotonate tautomerase family of enzymes: How nature makes new enzymes using a $\beta-\alpha-\beta$ structural motif. Arch Biochem Biophys 402: 1-13. doi:10.1016/S0003-9861(02)00052-8

Whitman CP, Aird BA, Gillespie WR, Stolowich NJ (1991) Chemical and enzymic ketonization of 2-hydroxymuconate, a conjugated enol. J Am Chem Soc 113: 3154-3162. doi:10.1021/ja00008a052

Wills ED (1956) Enzyme inhibition by allicin, the active principle of garlic Biochem J 63: 514-520. doi:10.1042/bj0630514

Winterbourn CC, Hampton MB (2008) Thiol chemistry and specificity in redox signaling. Free Radic Biol Med 45: 549-561. doi:10.1016/ j.freeradbiomed.2008.05.004

Wüllner D, Haupt A, Prochnow P, Leontiev R, Slusarenko AJ, Bandow JE (2019) Interspecies comparison of the bacterial response to allicin reveals species-specific defense strategies. Proteomics 19: 1900064. doi:10.1002/pmic.201900064

Xin X-F, He SY (2013) Pseudomonas syringae pv. tomato DC3000: A model pathogen for probing disease susceptibility and hormone signaling in plants. Annu Rev Phytopathol 51: 473-498. doi:10.1146/annurev-phyto082712-102321

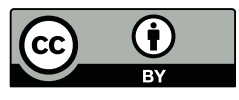

License: This article is available under a Creative Commons License (Attribution 4.0 International, as described at https://creativecommons.org/licenses/ by/4.0/). 